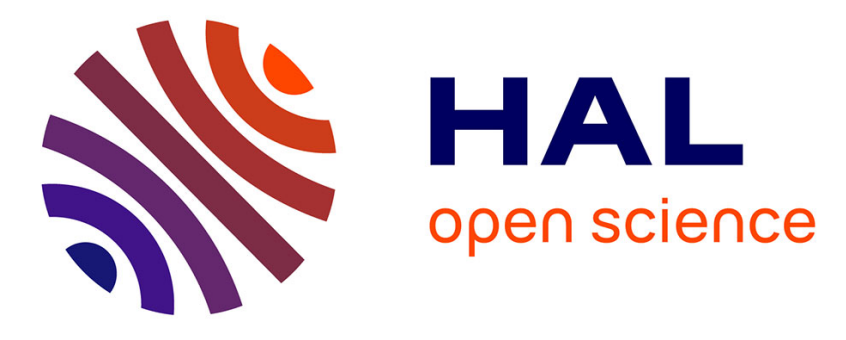

\title{
Determination of extreme sea levels along the Iberian Atlantic coast
}

André B Fortunato, Kai B Li, Xavier B Bertin, Marta B Rodrigues, Belen Martin Miguez

\section{To cite this version:}

André B Fortunato, Kai B Li, Xavier B Bertin, Marta B Rodrigues, Belen Martin Miguez. Determination of extreme sea levels along the Iberian Atlantic coast. Ocean Engineering, 2016, 111, pp.471-482. 10.1016/j.oceaneng.2015.11.031 . hal-01453448

\section{HAL Id: hal-01453448 https://hal.science/hal-01453448}

Submitted on 2 Feb 2017

HAL is a multi-disciplinary open access archive for the deposit and dissemination of scientific research documents, whether they are published or not. The documents may come from teaching and research institutions in France or abroad, or from public or private research centers.
L'archive ouverte pluridisciplinaire HAL, est destinée au dépôt et à la diffusion de documents scientifiques de niveau recherche, publiés ou non, émanant des établissements d'enseignement et de recherche français ou étrangers, des laboratoires publics ou privés. 
1

2 3

4

5

6

7

8

9

10

11

12

13

14

15

16

17

18

19

20

21

22

$23{ }^{*}$ Correspondingauthor:André Fortunato, afortunato@Inec.pt,+351 218443425

24

LNEC, Avenida do Brasil, 101, 1700-066 Lisbon, Portugal

\section{Determination of extreme sea levels along the Iberian Atlantic coast}

Submitted toOceanEngineering,October, 2014

Revised, September, 2015

André B. Fortunato ${ }^{1}, \mathrm{Kai}_{\mathrm{Li}}{ }^{1}$, Xavier Bertin $^{2}$, Marta Rodrigues $^{1}$, BelénMartínMiguez ${ }^{3}$

\begin{abstract}
${ }^{1}$ National Laboratory for Civil Engineering, Estuaries and Coastal Zones Division Av. do Brasil, 101, 1700-066 Lisbon, Portugal. \{afortunato, kaili, mfrodrigues\}@Inec.pt

${ }^{2}$ UMR 7266 LIENSs, CNRS - Université de La Rochelle, 2 rue Olympe de Gouges, 17000 La Rochelle Cedex, France. xbertin@univ-Ir.fr

${ }^{3}$ Centro Tecnológico del Mar, Vigo, Spain. bmartin@cetmar.org
\end{abstract}




\section{Abstract}

Extreme sea levels along the Atlantic lberian coast are determined through the development and application of a numerical model for tides and surges, followed by a statistical analysis of the model results. A recent statistical method is assessed using 131 years of data from the Brest tide gauge, and the number of years of data required for an accurate statistical analysis is estimated. The statistical method is extended to consider tide-surge interactions, but they are shown to be small in the study region. The model covers a large portion of the NE Atlantic, with a 250 m resolution in the Portuguese shelf. In the Iberian shelf, RMS errors of tides are of the order of $5 \mathrm{~cm}$, and extreme sea levels are under-estimated by about $10 \mathrm{~cm}$. Differences between sea level statistics obtained from model output and observations are of the order of $5 \mathrm{~cm}$ in the study region. Simulation of tides and surges between 1980 and 2010, followed by a statistical analysis of the results, provide the extreme levels along the Iberian Atlantic coast for different return periods. Results reveal the increase of extreme sea levels from south to north and the importance of local effects.

Keywords: Numerical modeling; statistical analysis;tide; storm surge;SELFE

\section{Introduction}

There is an increasing concern over the flooding of coastal areas. On the one hand, the hazard is increasing due to climate change. Sea level rise directly impacts extreme water levels. In shallow seas, sea level rise can also enhance the tidal amplitude, further affecting extreme water levels (Arnset al., 2015). In some parts of the globe, growing storminess also increases the frequency and severity of extreme events. For instance, Bertin et al. (2013) showed a significant increase of the significant wave height over the whole North Atlantic Ocean during the past century. On the other hand, the vulnerability is also increasing due to the continuous migration of the populations and economic activities to the coast (Nicholls et al., 2007). In Europe, this concern has translated into major legislation (the European directive on the assessment and management of flood risks, 2007/60/EC) and significant research funding in the $7^{\text {th }}$ EU research framework (Quevaullier, 2011) and the new H2020 EU research framework (Perini et al., 2015).

The dominant mechanisms responsible for the flooding vary across the globe. Storm surges dominate in some areas, such as the Gulf of Mexico and the Gulf of Bengal, while tides are also important in many parts of the world (Zhang and Sheng, 2013). Wind waves can also induce a significant setup close to the coast. Bertinet al. (2009) estimate this setup at several 
tens of $\mathrm{cm}$ under energetic waves. Similarly, Bertinet al. (2015) estimated the wave setup in harbors sheltered from agitation, in the region of La Rochelle, at 0.10 to $0.20 \mathrm{~m}$ for a classical storm with an offshore significant wave height of 7-10 m. Finally, low-frequency, infra-gravity waves can also play a role.As in many other similar studies (e.g., Haigh et al., 2010), the focus here is on the stillwater levels, i.e., the effects of surface waves are ignored.

Determining the hazard from tide gauge data entails major difficulties. Firstly, few tide gauges have time series long enough to provide reliable statistics. For instance, in Portugal, only the Leixões (Araújoet al., 2013), Aveiro (Fortunato et al., 2013), Cascais and Lagos tide gauges have multi-decadal time series. Secondly, some stations are not representative of coastal conditions because they are located inside estuaries. Estuarine water levels differ from sea levels not only due to shallow water processes but also due to the effect of river flow. Thirdly, most annual time series have gaps due to instrument malfunctioning, which severely limit the applicability of statistical methods to determine return periods associated with extreme sea levels. Finally, it is possible that the occurrence of data gaps is not random, but often associated with storms (e.g. Breilhet al., 2014). If this hypothesis was true, as suggested by Figure 1, statistical analyses of extreme sea levels based on tide gauge data would systematically underestimate the true extremes. This problem can be mitigated by combining testimonial with observational data, but this approach can by very time-consuming (Bulteau et al., 2015).

As an alternative to measured sea levels, process-based numerical models avoid the four previous difficulties. Provided adequate computational resources and proper data for their setup, forcing and validation, models can produce long and continuous time series of sea surface height, which can be used to determine the return periods associated with extreme sea levels. This approach has been followed recently by Batstone et al. (2013), Zhang and Sheng(2013) andHaigh et al. (2014a, b) for the coasts of the UK, western northAmerica and Australia, respectively.

This paper aims at characterizing the extreme sea levels along the lberian Atlantic coast. Due to the limited number of long tidal records in this area, the extreme levels are determined using 31 years of hindcast simulations of tides and surges. As in the similar studies mentioned above, the focus here is on the still water levels, i.e., the effects of surface waves is ignored. Model results are statistically analyzed to determine sea levels associated with different return periods. To assess the errors introduced by the statistical analysis, the statistical method is first applied and assessed using 131 years of measured water levels from the Brest tide 
gauge(France), one of the longest time series in the world (Wöppelmannet al., 2007).Given the difficulty in considering tide-surge interactions in the statistical analyses, the importance of these interactions is briefly assessed.

The paper is organized as follows. Section 2 describes the statistical analysis method, illustrating its application to the Brest data. Section 3 describes the model application and validation and discusses the results.

\section{Statistical method: description and assessment}

\subsection{Background}

The return periods for extreme sea levels are usually determined using water levels measured at tide gauges. However, measured time series are usually short (typically a few decades) relative to the return periods that need to be determined (typically 10 to 1000 years). This limitation is often aggravated by gaps in the data, associated with instrument malfunctioning. As a result, the tails of the empirical statistical distributions of extreme levels usually have very few data points, thus uncertainties are very high for large return periods. In some cases, the largest storms can appear as outliers in the empirical statistical distributions, casting doubts on their return period (Bardet et al., 2012).

Different methods have been proposed to determine the statistics of extreme sea levels (see Haigh et al., 2010 and Batstone et al., 2013 for recent reviews). Direct methods compute these statistics based on measured extremes. The simpler approach (AMAX) uses only the set of annual maxima, while other approaches (Peak Over Threshold) use several maxima per year (Tawn, 1988; Coles, 2001; Arnset al., 2013). In any case, the number of data points used to construct the statistical distribution remains small, and the uncertainty in the tail of the distribution is large. In an attempt to overcome this shortage,Bernardaraet al. (2011) and Bardet et al. (2012) combined data from several coastal stations in the same region. This approach succeeded in dissipating the doubts about the outliers. However, the dominant physical processes are not necessarily the same at the different stations (e.g., due to different extents of the continental shelf) which casts some doubts on the physical basis of the approach. Furthermore, if the same storm is measured at two nearby stations, the data will not be strictly independent. This limitation was addressed by Weiss et al. (2014).

The Joint Probability Method (JPM, Pugh and Vassie, 1980) constitutes a significant improvement over direct methods by splitting the measured sea level signal into tidal and surge components, and performing independent statistics for each component. The probability 
distribution of extreme sea levels is then computed through the convolution of the probability distributions of the two components. However, this method has its own shortcomings (Haigh et al., 2010):

1. It assumes that consecutive hourly measurements of sea levels are independent, which is false as both the tide and the surge signals exhibit strong temporal dependence.

2. It assumes that the empirical non-tidal distribution is a sufficiently good estimate of the true distribution. Whilst it is acceptable for most of the range, it is restricted near the extremes, the region of prime interest.

3. Confidence intervals cannot be calculated.

4. It is more complex than the direct methods because two forms of dependence must be accounted for: seasonality (i.e. larger surges are more prevalent in winter) and tide-surge interaction (i.e. in many regions, non-linear interactions between the tidal and non-tidal components tend to cause surge maxima to occur most frequently at certain phases of the tide).

Tawn and Vassie (1989) and Tawn (1992) revised the JPM by fitting an extreme value distribution to the tail of the extremes distribution. Batstone et al. (2013) further improved the JPM by analyzing the skew surge, rather than the instantaneous surge (Skew Surge Joint Probability Method). The skew surge, defined as the difference between the predicted tide and the observations at high tide, is less sensitive to phase lags than the instantaneous surge. However, Batstone et al. (2013) found that this approach led to unphysical results in about $25 \%$ of the stations used in their study. More recently, Mazas et al. (2014) further improved the method. Serafin and Ruggiero (2014) developed a method that splits not only the tidal and surge signal, but also wave runup. While most of the shortcomings of the JPM seem to be overcome, the improved JPM has grown progressively more complicated and difficult to implement.

In summary, determining the return periods of extreme sea levels is a difficult task, which entails a significant uncertainty. Significant efforts to address this problem have led to the development and improvement of many methods, with varying degrees of complexity. A consensus on the best method or methods remains to be reached.

\subsection{Method description}

The method used herein, an extension of the one proposed by Fortunato et al. (2013), is akin to the JPM in the sense that the signal is split into various components with a different physical 
origin. These components are modeled individually, then added together to generate a large set of synthetic yearly time series. An empirical statistical distribution is then determined based on the AMAX method. The large number of synthetic yearly time series (e.g., about 300,000 for 20 years of data in Fortunato et al., 2013) mitigates the uncertainty associated with the shortage of data. A very similar approach was proposed by Haigh et al. (2014b).

The method proceeds as follows. The observed elevation signal, $\eta$, is split into several components:

$$
\eta=\eta(\text { long term })+\eta(\text { tide })+\eta(\text { tide } / \text { surge })+\eta(\text { residual })
$$

- $\eta$ (long term) is the Mean Sea Level. Here, it is computed as a linear trend in time, determined by a regression analysis of the annual means of the measured data. Higher order approximations to the mean sea level dependence on time can easily by adopted.

- $\eta$ (tide) is the tidal signal. Tidal constituents are determined through a harmonic analysis of the long-term time series. The tidal signal can then be reconstructed for any given year by harmonic synthesis, given the appropriate nodal factors.

- $\eta$ (tide/surge) represents the average interaction between tide and surge. This term will be neglected for the time being, and its evaluation will be discussed in Section 2.5.

- $\eta$ (residual) includes all other factors and is thus computed as the difference between the observed elevation nand the previous terms.

The approach proceeds as follows. First, the yearly mean sea level is determined and modeled through a regression function (see Figure 2 for an example for the Brest station). The tidal constituents are determined next by harmonic analysis of the whole series. Finally, hourly residuals are obtained by subtracting the long-term trend and the tidal synthesis from the data. If required, these residuals may be split in distinct components, as will be detailed below. In a second step, yearly time series are synthesized by varying the following factors independently: 1) the tide, over a period of 19 arbitrary consecutive years. Using this period allows taking into account the 18.6 years lunar nodal cycle, which has been shown to affect extreme sea levels (e.g., Eliot, 2010). An analysis of the yearly standard deviation of the tidal signal at Brest (not shown) reveals a variability with an amplitude of $10 \mathrm{~cm}$ and a period of 19 years.

2) the hourly residuals obtained previously, for a user-selected set of years. If these residuals are further split into different components, these are varied independently as well.

3) the phase lag between the synthesized tide and the observed residuals. This phase lag, 
which varies between -15 and +15 days with a time step of 1 hour, allows any observed storm surge to occur at different times in the tidal cycle and in the neap-spring cycle. Hence, extreme sea levels higher than those observed are obtained. While the choice of the phase lag is somewhat arbitrary, a sensitivity analysis showed that using \pm 30 daysinstead does not affect the results significantly (not shown).

The time step mentioned above was set to 1 hour according to the value available in most old tide gauge records. Reducing this time step to a few minutes would probably lead to slightly higher maxima but was not attempted herein.

The number of yearly synthetic time series obtained by this procedure is given by the product of the number of consecutive years of tides (19), the number of years of data (up to 131 in the analysis of the Brest data shown below, and 31 for the model results described in the next section) and the number of hours in 30 days (721). The typical number of synthetic time series is thus in the order of $10^{5}-10^{6}$.

The empirical statistical distribution is then obtained by the AMAX method. For consistency, the Mean Sea Level ( $\eta$ (long-term)) is removed from the time series analyzed. To obtain the sea level associated with a given return period for a particular year, the Mean Sea Level for that year (red curve in Figure 2) must be added to the results.

This approach overcomes the major problems associated with the JPM listed above. First, the various components are modeled as time series, thus retaining their temporal dependence. This is an advantage over classical convolution methods, which ignore the strong dependence between the water levels at two consecutive times (Haigh et al., 2010). Secondly, the behavior of the extremes is assessed through a convergence analysis, in order to determine how many years of data are required for a converged solution for a particular return period. This analysis allows the estimation of confidence levels. Finally, the seasonality of the tidal and surge signals is taken into account by limiting the phase lag between the two signals to a minimum (15 days). Tide-surge interactions can also be included in the method, as illustrated below. The major limitation of the method is that it cannot assume storm surges higher than the ones present in the input data.

\subsection{Method assessment}

The new method is compared to the AMAX method with a GEV distribution by Fortunato et al. (2013) and to JPM by Lopes and Dias (2015). However, those assessmentsare limited by the short duration of the observational record used (20 years). Herein, one of the world's longest 
tidal records is used to provide a more detailed assessment of the new method. The data from the Brest tide gauge are available from the University of Hawaii Sea Level Center (1848-2007) and REFMAR (2008-2011). The data were first screened, and minor problems were corrected. Years with measurement gaps occurring during the maritime winter (October - March) were discarded, as there was the possibility that a significant storm surge went unmeasured. The remaining 131 years were considered in the analysis. For the gaps occurring in the maritime summer, residuals were assumed to be zero since they are unlikely to generate yearly maxima. The harmonic analysis of the observations was performed with the software MAS (Simon, 2007) using about 100 constituents.

A convergence analysis was first performed to determine how the uncertainty of the method varies with the number of years available, and how many years of data are required to obtain reliable values for the return period. As expected, the uncertainty grows with the return periods. Results indicate that with 30-40 years of data, the maximum elevations for return periods of 100 years or less can be determined with an uncertainty of the order of a few centimeters (Figure 3a). However, this result may depend on the particular years used in the analysis. The major recorded storm surge to have hit Brest, in 1987, exceeds all other recorded storms by far (Figure 4). If the year of 1987 is included in the analysis, results change significantly, in particular for the 1000 year return period (dashed lines in Figure 3b). These results indicate that the analysis should preferably be restricted to return periods of 100 years or less. However, because extremes associated with 1000 year return periods are often required for management purposes, they were also included in this study.

The return periods obtained with the new method were compared with the application of the AMAX method to the 131 years of data. A Gumbel distribution was fitted to the empirical cumulative distribution function by a least squares approach, following Haigh et al. (2014b) who found it to provide better results than the GEV distribution. Three alternative approaches were followed to determine the adjustment parameters. The direct fitting of the empirical cumulative density function led to a good agreement of the data for low return periods (up to 10 years) but diverged significantly from the empirical function for larger return periods. In contrast, fitting the empirical return period function led to a good adjustment for return periods above 10 years, but failed for low return periods. The most well-balanced adjustment was obtained by fitting the logarithm of the empirical return period function. Using this adjustment, there is a reasonable agreement between the Gumbel distribution and the empirical functions obtained with the new method (Figure 3a): for return periods between 10 and 1000 years, the 
discrepancy between the two curves does not exceed $4 \mathrm{~cm}$. The difficulty in finding the best curve-fitting algorithm when adjusting a theoretical distribution to an empirical function constitutes an additional disadvantage of the AMAX method that the method proposed herein avoids.

As one of the reviewer pointed out, the statistical method used herein does not address the problem of the small timing errors in observations or tidal predictions. This problem stems from the small phase lags between the tidal predictions and the observations, which can lead to artificially high residuals, hence to an overestimation of the extreme water levels. However, while these phase lags are common in observation records, particularly in old ones, they should not occur in modeled time series. Whatever phase errors may exist in the model time series will be reproduced in the tidal synthesis, thereby avoiding phase differences between the two time series. Hence, this statistical method is particularly suited to time series generated by numerical models.

\subsection{Time evolution of the sea level extremes}

Based on these results, sets of 41 years were analyzed using a running window approach to determine the maximum elevations for different return periods. Results suggest a possible upward trend in the maximum elevation for all return periods, even excluding the effect of the rising mean sea level (Figure 5a). This result would be consistent with the increase in significant wave height found in this region by Bertinet al. (2013) for the period 1900-2010. However, for the smaller return periods, this increase is an order of magnitude smaller than the rise in mean sea level $(1.27 \mathrm{~mm} /$ year at this station, Figure 2): the trends are 0.18 and $0.17 \mathrm{~mm} /$ year for the 10 and 100 year return periods, respectively. Results also indicate a $1.1 \mathrm{~mm} /$ year growth trend for the 1000 year return period. However, considering the uncertainty shown above for this return period, this result cannot be considered significant. Close inspection of Figure $5 \mathrm{~b}$ further shows that this trend is determined to a large extent by the last three data points in the curve, i.e., the ones that are computed using data from 1987. Hence, this analysis does not support the conclusion of a growth of the extreme sea levels at Brest during the last 150 years, apart from the effect of sea level rise which is excluded from this analysis. This result is consistent with a previous study that found that the increase in sea level extremes is mostly a result of sea level rise (Menendez and Woodworth, 2010).

\subsection{Importance of tide-surge interactions}

Tide-surge interactions can represent a significant fraction of the residuals, in particular in shallow areas. For instance,Idieret al.(2013) show that these interactions can represent $50 \%$ 
of the maximum surge in the English Channel. Various physical mechanisms have been proposed to explain these interactions. First, tidal propagation can be accelerated (decelerated) by a positive (negative) surge (Horsburgh and Wilson, 2007). This acceleration leads to a phase shift between the measured and predicted tide which translates into positive (negative) residuals during the rising (falling) tide. Secondly, the wind effect (i.e., the wind stress divided by depth in the shallow water equations) is inversely proportional to the water depth. The storm surge will thus tend to be higher at low tide, in particular in shallow areas with a large tidal range (Horsburgh and Wilson, 2007; Antony and Unnikrishnan, 2013). A sensitivity analysis suggests that the first mechanism is small except for very wide and shallow continental shelves, while the latter can lead to tidal modulations of the order of a few tens of centimeters (see Appendix). Other mechanisms have been identified, such as the increase in bottom friction at low tide (Rego and Li, 2010) and advection (Idieret al., 2013). Hence, the relation between the tide and the residual is complex and strongly space-dependent. This relationship is illustrated for Brest in Figure 6, where the number of occurrences of residuals higher than 20,40,60 and $80 \mathrm{~cm}$ were plotted against the tidal time. The tidal time is defined here as:

$\phi=\left(t-t_{1}\right) /\left(t_{2}-t_{1}\right)$

where $t_{1}$ and $t_{2}$ are two consecutive times of high water, and $t$ is time. The curves on Figure 6 were generated using 131 years of data. If the residual was independent of the tidal phase, these curves should be approximately constant. The signals whichappear show that the residuals depend on the tidal phase.The signal is clearest for the lower thresholds, probably due to the higher number of occurrences. Horsburgh and Wilson (2007) present similar signals at other tidal stations. However, these signals vary significantly from station to station, highlighting the complexity of this dependence.

As a result of this dependence, the average residual varies along the tidal cycle, and this average increases with the low-frequency surge (Figure 7). The low-frequency surge represents the daily mean sea level, obtained by filtering the observations with a Demerliac filter (Demerliac, 1974). The tide-surge interaction signal also increases with the tidal amplitude, although to a lower extent (not shown). Figure 7 shows that, for a particular location, the knowledge on the phase of the tide provides information on the residual.

If the tide-surge interactions are strong, the statistical method described above should take them into account by using the data to model term $\eta$ (tide/surge) in eq. (1). In the case of Brest, the tide-surge interaction signal is weak even when low-frequency surges are high: about $5 \mathrm{~cm}$ 
for low-frequency surges over $30 \mathrm{~cm}$. Therefore, these interactions should not affect sea level extremes significantly at this site. Mazaset al. (2014) also found the impact of considering tidesurge interactions in the evaluation of extreme sea levels at Brest to be negligible. To verify this conclusion, and to illustrate how the method can be adapted to take into account the tidesurge interaction, the term $\eta$ (tide/surge) is computed as a function of the predicted tidal phase, using a curve similar to the ones in Figure 7 but for all surges. This curveis removed from the values of $\eta$ (residual) computed previously, then added as a function of $\eta$ (tide) when reconstructing the synthetic time series.

Results show that the maximum elevations for a given return period increase only by a few centimeters at Brest when the tide-surge interaction is considered(Figure $5 b$ ). This increase is associated with the average residual at high tide, which is positive (Figure 7). However, this average residual can be negative at other places (Horsburgh and Wilson, 2007), so it cannot be assumed that considering this effect will always increase the maximum elevations.

Statistical methods to analyze extreme sea levels have typically dealt with the tide-surge interactions by analyzing the so-called skew surge (e.g., Bardet et al., 2011). The skew surge is the difference between the maximum observed sea level during a tidal cycle and the corresponding predicted high tide. The underlying hypothesis is that the skew surge is not affected by phase lags in the observed tides. Hence, the skew surges would be independent of time of arrival of the storm surge relative to the tide. However, Idieret al. (2012) showed that the skew surges can also depend on the tidal amplitude, hence do not eliminate the tide-surge interaction effects. The approach introduced herein appears therefore as an alternative to take the tide-surge interactions into consideration.

Even though this approach provides a possible way to take tide-surge interaction into account in the determination of extreme sea levels, it must be recognized that it is cumbersome, as the effects of tide-surge interactions on the sea levels vary strongly with the location. Also, the tide-surge interaction could be easily modeled in Brest because the signal is very clear. However, most stations and hindcast databases have much shorter records, which may result in more noisy signals, more difficult to model.

For the particular case of Brest, in spite of the wide continental shelf, a macro-tidal range and strong surrounding tidal currents, the effect of tide-surge interactions on extreme sea levels is small. In the Iberian Atlantic coast, these effects have been shown to be very small due to the narrow continental shelf (Fanjul et al., 1998) and will be neglected henceforth. 


\section{Extreme sea levels along the Iberian Atlantic coast}

\subsection{Study site}

The Iberian Atlantic coast extends from the Strait of Gibraltar, in the south, to the SpanishFrench border in the north (Figure 8). The continental shelf is about $20-70 \mathrm{~km}$ wide. Tides are semi-diurnal. The amplitude of M2 is about $1.0 \mathrm{~m}$ in most of the south and western coast, and increases to $1.4 \mathrm{~m}$ along the north coast (Fortunato et al., 2002). Storm surges increase from south to north. For a 100 year return period, the storm surges at four coastal stations along the Portuguese coastwere estimated to be between 70 and $90 \mathrm{~cm}$ (Andrade, 2006). These values could be slightly underestimated, as an observed value above $1 \mathrm{~m}$ was reported in Aveiro (Fortunato et al., 2013). The western and northern coasts have very energetic wave regimes, as they are directly exposed to the waves coming from the Atlantic Ocean. For instance, the $90^{\text {th }}$ percentile of the offshore $\mathrm{Hs}$ varies in the range 4-6 $\mathrm{m}$ (Dodet et al., 2010).Significant wave heights (Hs) grow from south to north.

The coast has many low-lying areas, including sand spits and barrier islands that are occasionally overtopped and breached. Many areas surrounding major estuaries and lagoons are also close to mean sea level. For instance, the zone surrounding the Ria de Aveiro between 0 and $4 \mathrm{~m}$ above mean sea level has an area of about $160 \mathrm{~km}^{2}$ (Fortunato et al., 2013). There are historical records of severe damages and casualties associated with storm surges in the Portuguese coast. Pereira and Coelho (2013) report 86 episodes of overtopping and 21 episodes of dune destruction by the sea since 1850 in the Aveiro region alone. Several episodes of inundation in the Ria Formosa and in the Tagus estuary are illustrated in Carrasco et al. (2012) and in Tavares et al. (2015), respectively.In February 15, 1945, a major storm hit the Iberian coast at high tide and caused extensive damage (Muir-Wood, 2011; Freitas and Dias, 2013): downtown Lisbon and Sesimbrawere flooded, several ships sank, railways and houses were destroyed, and a new inlet, $1000 \mathrm{~m}$ wide, was breached in the Ria Formosa. At least 130 casualties were reported in Portugal and Spain, although not all can be attributed to flooding.If this storm occurred today, the estimated damage in the Iberian Peninsula would exceed 6 billion euros (Muir-Wood, 2011). More recently, the damages caused by the 2014 Hercules storm caused tens of millions euros worth of damage along the Portuguese coast.

\subsection{Model description and application}

The hydrodynamics were simulated with the community model SELFE (Zhang and Baptista, 2008), a semi-implicit finite element shallow water model, which targets cross-scale applications. The implicit nature of the model and the use of an Eulerian-Lagrangean method for advection avoid Courant number restrictions, allowing the use of large time steps. SELFE 
$414 \gamma^{2}=\operatorname{Var}(\mathrm{O}-\mathrm{M}) / \operatorname{Var}(\mathrm{O})$ $300 \mathrm{~s}$.

\subsection{Model assessment}

is the core of a suite of community models, which include modules for ecosystem dynamics (Rodrigues et al., 2009, 2012), fecal contamination dispersion (Rodrigues et al., 2011), oil spill dynamics (Azevedoet al., 2014), sediment transport and morphodynamics (Pinto et al., 2012, Dodet, 2013) and wave-current interaction (Bruneauet al., 2011, Roland et al., 2012). The simulations were performed with the two-dimensional version of Zhang et al. (2011), providing the free-surface elevations and depth-averaged velocities.

The model covers the domain between latitudes $26^{\circ}$ and $70^{\circ} \mathrm{N}$, and from longitude $19.5^{\circ} \mathrm{W}$ to the European coastline (Figure 8). The grid has about 150,000 nodes and its resolution is highest along the Portuguese coast, where it reaches $250 \mathrm{~m}$, and in the western coast of France. The bathymetry is mostly taken from EMODnet (www.emodnet-bathymetry.eu), with small corrections and add-ons. The model is forced by tides, wind and atmospheric pressure. Tidal boundary conditions (18 constituents: Z0, O1, K1, P1, Q1, M2, S2, N2, K2, 2N2, MU2, NU2, L2, M3, M4, MS4, MN4, M6) are taken from the regional tidal model of Pairaudet al. (2008) and tidal potential is included inside the domain (11 constituents: SSA, MM, MF, O1, $\mathrm{K} 1, \mathrm{P} 1, \mathrm{Q} 1, \mathrm{M} 2, \mathrm{~S} 2, \mathrm{~N} 2, \mathrm{~K} 2$ ). Winds and atmospheric pressure from CFSR reanalysis (Sahaet al., 2010), with a 1 hour resolution, are used to force the model inside the domain, and the inverse barometer effect is added at the open boundaries. The wind stress is computed with a wind-dependent drag coefficient following Pond and Pickard (1998). The time step is set to

The model was not calibrated. A preliminary sensitivity analysis showed that the errors tended to decrease slightly in the northern European stations for larger values of the Manning coefficient, but were insensitive to this parameter to the south of France. Hence, a constant Manning coefficient of $0.03 \mathrm{~m}^{1 / 3} / \mathrm{s}$ was used. The diffusion coefficient was set to zero.

Several error measures were used to assess the model performance. Root mean square (RMS) errors were used to analyze the performance of the tidal model alone. RMS errors were computed from observed and modeled time series synthetized with the major semi-diurnal (M2, S2, N2) and diurnal(O1 and K1)constituents. The normalized variance of the difference between model and observations provides an integral measure of model performance (Zhang and Sheng, 2013). This error norm is defined as:

whereVar represents the variance, and $\mathrm{O}$ and $\mathrm{M}$ stand for the observations and predictions, 
respectively. The peak error range was used to quantify the ability of the model to capture the peak elevations. The peak error range is defined as the maximum positive and negative differences between the observed and the modeled high tides. Note that the observed and modeled high tides may not occur exactly at the same instant, so phase errors do not affect the peak range. Finally, statistics of extreme sea levels were also compared to those derived from observations or other models, where available.

The model was first validated for tides. Root mean square errors for the 5 representative constituents at stations in the southern part of the domain are typically smaller than $5 \mathrm{~cm}$ (Figure 9a). These errors are smaller than or equivalent to those presented in previous similar applications (Fortunato et al., 2002, 2011).These absolute errors are higher inthe French coast, possibly due to the higher tidal ranges.

The full tide and surge model was validated next for the 2009-2010 winter. This period was selected because it was a particularly violent winter. In February, the Xynthia storm generated surges over $1.5 \mathrm{~m}$ in the south-western French coast, killing 47 people and causing an estimated 1.5 billion euros of damage (Bertinet al., 2012). The same storm had significant impacts in the Portuguese coast as well (Guerreiroet al., 2015).

Normalized errors (Figure 9b) and peak errors (Figure 9c) show that the model captures the variance and the peaks of the measured signal in most of the domain (i.e., in the Iberian Peninsula and further south): the normalized variance $\gamma^{2}$ is smaller than $3 \%$ and the peak errors are typically below $20 \mathrm{~cm}$. However, themodel accuracy degrades progressively along the French western coast.

This varying spatialaccuracy of the model can be partly attributed to the coarser grid resolution in the northern part of the domain, which was included to simplify the definition of the boundary conditions. However, the grid is also coarse in the Macaronesia region, where errors are very small. Hence, the variability of the model errors should be mostly attributed to the different physical processes that dominate the generation of extreme sea levels.

Storm surges are generated by both strong wind and low atmospheric pressure. The wind effect is amplified by extensive shallow areas because the wind stress is divided by depth in the shallow water equations. In contrast, the atmospheric pressure term in the governing equations does not depend on depth. As a result, the relative importance of the two forcing agents on the storm surge can differ significantly depending on the extent of the continental shelf. In the present model application, the continental shelf is much wider in the northern part 
of the domain than in the southern part (Figure 8). Hence, the wind stress should play a more important role in the generation of storm surges in the northern part of the domain than in the south.In the Iberian Atlantic shelf, the wind contribution to the storm surges was estimated at about 30\% (Fanjulet al., 1998). Since atmospheric models reproduce air pressure better than wind velocity, the difference in the dominant forcing term should also help explaining the variability of the model accuracy.In particular, the resolution of the wind fields used herein is relatively coarse, which tends to smooth the extreme events. For instance, Stopa and Cheung (2014) show that CFSR underestimates the higher wind speeds. This limitation of wind models can be overcome using parametric winds (e.g., Zhangand Sheng, 2013), but this approach was mostly applied to tropical cyclones and was not followed herein. Also, the evaluation of wind stress depends on an empirical drag coefficient, which can introduce additional errors for specific storms. The errors for the Xynthia storm in La Rochelle illustrate these errors. The model underestimates the peak sea level duringXynthia by about $70 \mathrm{~cm}$ (Figure 9c), of which about $0.5-0.6 \mathrm{~m}$ can be attributed to the representation of the surge. The inability of the model to reproduce the Xynthia storm in the French coast in general, and at La Rochelle in particular, is due to the very specific track of that storm (Bertinet al., 2012). Contrary to most storms in this region, the Xynthiatrack was SW-NE. Xynthia hit Europe first in the north of Spain, then continued over the Bay of Biscay, where it generated the waves that hit the French coast. The very high steepness of these young waves increased the transfer of momentum from the atmosphere to the ocean, exacerbating the wind setup. The adequate representation of the Xynthia storm surge in the French coast thus requires the coupling between a wave and a circulation model, to include the effects of waves on the surface stress (Bertinet al., 2012). Hence, the present implementation of the model significantly underestimates the Xynthia storm surge in the French coast. Since storms following this particular track generate some of the highest surges along this coast (Breilhet al., 2014), the model will underestimatesome major extreme sea levels in the French coast.

Finally, the return periods associated with extreme levels at four stations were computed with the model results and compared to a similar evaluation using data fromCascais, Aveiro and Brest (Figure 9d). Results indicate uncertainties in the extreme sea levels of the order of $5 \mathrm{~cm}$ at the Iberian stations: up to 8 and 15 in Cascais and Aveiro, respectively. Considering the analysis of the Brest data, this error is of the same magnitude as the uncertainty associated with the use of only 31 years of data. Again, and as for the peak errors, the discrepancy between the model and data statistics is higher at the Brest station $(10-20 \mathrm{~cm})$. Results at Bilbao were also compared with those performed by Marcos et al. (2012) with a different 
482 model and a different statistical approach. The small discrepancies between the two, up to $4838 \mathrm{~cm}$, provide further confidence in the present approach.

484 The comparison between the statistics based on the model and the observations suggests that 485 the model tends to underestimate the extreme sea levels. This underestimation occurs in 486 Cascais, Brest and in Aveiro for the higher return periods. This behaviour is probably due to 487 the lack of wave setup in the model.

488 As a final assessment of the model, Figure 10 compares hourly residuals computed from 489 model results observations. The event corresponds to a storm that hit the Portuguese coast on 490 November 7 1982, when offshore significant wave heights reached $8 \mathrm{~m}$ and the storm surge 491 exceeded $50 \mathrm{~cm}$.

492 The model correctly reproduces both the amplitude and phase of the surge in Cascais, with a 493 RMS error of $7 \mathrm{~cm}$ between days 306 and 314 (Figure 10). At Aveiro, the model is less 494 accurate, with a RMS error of $15 \mathrm{~cm}$. The model underestimates the surge at Aveiro, which is 495 consistent with the absence of wave setup in the model. Also,the larger errors at Aveiropartly 496 arise from the semi-diurnal signal in the residuals computed from observations, which is absent 497 in the residuals determined with the model. This semi-diurnal signal can have two possible 498 sources. The signal could be due to tide-surge interactions associated with the strong tidal 499 currents in the Aveiro tidal inlet, which are not represented by the model. Further work is 500 required to investigate the possibility of tide-surge interactions at these small scales.Also, the 501 semi-diurnal signal could be due to the small phase lags between the observations and the 502 tidal predictions. If this hypothesis is correct, then the discrepancies between the residuals 503 obtained from the model and from the observations do not correspond to model errors.

504 In summary, the model proved to be highly reliable to analyze extreme sea levels in the 505 southern part of the domain, even though its accuracy degrades further north. Hence, the 506 analysis of model results concentrates on the Iberian Atlantic shelf.

\section{3.4Results and discussion}

508 Hourly model results for the period 1980-2010 along the lberian coast were used to determine 509 extreme sea levels relative to local mean sea level for different return periods.Figure 11 510 illustrates these results for a return period of 100 years. The harmonic analysis is performed 511 on the fly by the model itself in a one-year simulation forced by tides alone. Only the 21 forcing 512 constituents and two major additional compound tides (MSf and 2MS6) are considered. 513 Otherwise, the statistical analysis proceeds as described in Section 2.

514 Results show that extreme sea levels increase significantly from south to north in this 
515 region:the difference between the extreme sea levelsin the south of Spain (Gibraltar) and the 516 south of France (St. Jean de Luz) is of the order of $2 \mathrm{~m}$. This growth is mostly due to the 517 northward increase of tidal ranges in this area:model results show an increase in maximum 518 tidal elevations between the south and the north of Spain exceeding $1 \mathrm{~m}$ (Figure 12).

519 At smaller spatial scales, results reveal strong increases of extreme sea levels in some 520 sheltered areas. For instance, the 100-year extreme sea level can increase by 0.2-0.3 $\mathrm{m}$ from 521 the mouth to the head in several funnel-shaped rias in the north of Spain (Figure 13). This 522 behaviour confirms the importance of basing extreme sea level analyses on model results 523 rather than coastal stations, which may not be representative of regional levels.

524 The differences between extreme sea levels for return periods of 20 and 1000 years appear 525 modest, increasing from about $0.1 \mathrm{~m}$ in the south of the Spain to $0.35 \mathrm{~m}$ in the south of France 526 (Figure 14). In the Portuguese coast alone, the extreme sea level for a 1000 return period is 527 only 18 to $25 \mathrm{~cm}$ higher than for a 20 year return period. By using the 100 year return period 528 for all planning purposes, the uncertainty associated with the choice of the return period is of 529 the order of $10 \mathrm{~cm}$ at most. This uncertainty is small in absolute terms, and is of the same 530 order of the model errors, and of those associated with the choice of the statistical method. 531 Hence, even though the European directive on the assessment and management of flood risks $532(2007 / 60 / E C)$ recommends that inundation maps are constructed for three different return 533 periods (to be specified by each member state), these differences suggest that, for many 534 engineering purposes, a single return period can be adopted in the Portuguese coast.Similarly, 535 a single return period could be used in southern Atlantic coast of Spain.

536 In spite of the good accuracy of the model indicated by the model-data comparisons presented 537 above, some processes which are not included in the model may introduce relevant errors in 538 some areas. First, the model used herein does not include waves and their effects on the 539 mean flow. Hence, both wave setup and infra-gravity waves are implicitly neglected. These 540 effects can increase extreme sea levels significantly in some areas. Also, coastal inundation is 541 prevented in this application, as the grid does not extend into land. Bertinet al. (2014) showed 542 that this approach can artificially increase the sea level at the coast, as the water that would 543 otherwise flood the land accumulates at the boundary. Hence, results may both over- and 544 under-estimate extreme sea levels at different locations.

\section{4. Summary and conclusions}

546 The extreme sea levels along the Iberian Atlantic coast were determined for different return 547 periods using a combination of multi-decadal hindcast simulations of tides and surges with a 
statistical analysis.

The statistical method was validated using 131 years of data from the Brest tide station. The method was extended to take into account tide-surge interactions, and it was shown that the effect of these interactions on extreme sea levels is negligible in the particular area analyzed. Results suggest that with 30-40 years of data, the maximum elevations for return periods below 100 years can be determined with an uncertainty of the order of a few centimeters.

The model covers a large portion of the NE Atlantic, and has a resolution of $250 \mathrm{~m}$ in the Portuguese shelf. The model was extensively validated for tides, surges and extreme sea levels. In the Iberian Atlantic shelf, RMS errors of tides are of the order of $5 \mathrm{~cm}$, and the model under-estimates extreme sea levels by about $10 \mathrm{~cm}$. More importantly, sea level statistics computed with the model results agree with those computed with tide gauge data.

Results provide a detailed picture of the extreme sea levels along the Iberian Atlantic coast. Extreme sea levels grow significantly from south to north, due to the increase in both tidal range and storm surges. Extreme levels can also increase locally by tens of centimetres in funnel-shaped rias. The differences between extreme sea levels for 20 and 1000 year return periods are modest, in particular in the Portuguese coast and in the southern Atlantic coast of Spain. These small differences suggest that for many engineering purposes it is sufficient to analyse a single representative return period in these regions.

The main limitation of the model is that waves are not modelled, thus wave setup and infragravity waves are neglected. Hence, future efforts should be directed towards reducing this source of errors. As a first approximation, combining regional wave hindcasts (e.g., Dodetet al., 2010) with empirical relations between wave characteristics and wave-induced setup (e.g., Holman, 1986; Stockdonet al., 2006) can improve the model results at acceptable computational costs.

\section{Acknowledgments}

This work was partially funded by the Fundaçãopara a Ciência e a Tenologia (projects MOLINES - PTDC/AAG-MAA/2811/2012 and ADAPTARIA - PTDC/AAC-CLI/100953/2008, and grants SFRH/BSAB/1308/2012 (ABF) and SFRH/BPD/87512/2012 (MR)). ABF andBMMalso acknowledge research grants received from the Région de Poitou (France) and AxenciaGalega de Innovación (Galician Government) during their visits to La Rochelle and Lisbon, respectively. This work makes use of results produced with the support of the Portuguese National Grid Initiative; more information in https://wiki.ncg.ingrid.pt.NCEP Reanalysis data provided by the NOAA/OAR/ESRL PSD, Boulder, Colorado, USA, from their web site at http://www.esrl.noaa.gov/psd/. The bathymetric metadata and Digital Terrain Model data products were partly derived from the EMODnet Bathymetry portal - www.emodnetbathymetry.eu. We thank Prof. Marta Marcos for providing the Bilbao results used in Figure 9d. Two anonymous reviewers are gratefully acknowledged for their constructive criticism. 


\section{Appendix: assessment of two tide-surge interaction mechanisms}

Two possible mechanisms for tide-surge interaction are briefly assessed. For simplicity, we consider a tide and a surge propagating along a continental shelf with a constant depth $H$.

The first mechanism notes that the celerity of the tide can be enhanced or reduced by a positive or negative surge, respectively (Horsburgh and Wilson, 2007). The resulting phase shift between the measured and predicted tide translates into residuals. This phase shift can be estimated as:

$$
\Delta \phi=\frac{L}{T}\left(\frac{1}{c}-\frac{1}{c^{\prime}}\right)
$$

Where $L$ is the extent of the continental shelf, $T$ is the tidal period, and $c=(g H)^{0.5}$ and $c^{\prime}=(g(H+s))^{0.5}$ are the celerity of the tide in the absence or in the presence of a surge $s$, respectively. The difference between the predicted tide (without phase shift) and the observed tide (with a phase shift $\Delta \phi$ ) constitutes the tide-surge interaction effect. However, an analysis of these effects shows that they are negligible except for very wide and shallow shelves (Figure A. 1).

Another mechanism of tide-surge interaction is the effect of total water depth on the depthaveraged wind stress. The wind forcing (i.e., the wind stress divided by depth in the shallow water equations) is inversely proportional to the water depth. The storm surge will thus tend to be higher at low tide, in particular in shallow areas with a large tidal range. The difference between wind setup at low and high tide $(\Delta \eta)$ can be estimated as:

$$
\Delta \eta=\frac{L C \rho_{a} W^{2}}{\rho g}\left(\frac{1}{H-A}-\frac{1}{H+A}\right)
$$

where $C$ is the empirical drag coefficient, $W$ is the wind speed, $A$ is the tidal amplitude, $\rho_{\mathrm{a}}$ and $\rho$ are the air and water densities, respectively, and $g$ is gravity.Figure A. 2shows that, for long and shallow continental shelves, this effect can reach $0.5 \mathrm{~m}$.

\section{References}

Andrade, C.,Pires,H.O.,Silva,P.,Taborda,R.,Freitas,M.C.,2006. Zonas Costeiras, in: Santos, F.D. andMiranda,P.(Eds.),Alterações climáticas em Portugal. Cenários, impactes e medidas de adaptação - Projecto SIAMII.Gradiva,Lisboa, in Portuguese.

Antony, C.,Unnikrishnan, A.S.,2013. Observed characteristics of tide-surge interaction along the East coast of India and the bay of Bengal, Estuarine, coastal and Shelf Science, 131: 6-11. 
Araújo, I.B., Bos, M.S.,Bastos, L.C.,Cardoso, M.M.,2013. Analysing the 100 year sea level record of Leixões, Portugal, Journal of Hydrology,481: 76-84.

Arns, A., Wahl, T., Haigh, I.D., Pattiaratchi, C., Jensen, J., 2013.Estimating extreme water level probabilities: a comparison of the direct methods and recommendations for best practice, Coastal Engineering, 81: 51-66.

Arns, A., Wahl, T., Jensen, J., 2015.The impact of sea level rise on extreme water levels in the northern part of the German Bight, Coastal Engineering, 96: 118-131.

Azevedo, A., Oliveira, A.,Fortunato, A.B.,Zhang, J.,Baptista,A.M., 2014. A cross-scale numerical modeling system for management support of oil spill accidents, Marine Pollution Bulletin 80, 1-2: 132 - 147.

Bardet, L., Duluc, C.-M., Rebour, V. and L'Her, J., 2011. Regional frequency analysis of extreme storm surges along the French coast, Nat. Hazards Earth Syst. Sci., 11, 16271639.

Batstone, C., Lawless, M., Tawn, J., Horsburgh, K., Blackman, D., McMillan, A., Worth, D., Laeger, S., Hunt, T., 2013. A UK best-practice approach for extreme sea-level analysis along complex topographic coastlines, Ocean Engineering, 71: 28-39.

Bernardara, P., Andreewsky, M.,Benoit,M., 2011.Application of regional frequency analysis to the estimation of extreme storm surges, J. Geophys. Res., 116, C02008, doi:10.1029/2010JC006229.

Bertin, X., Fortunato, A.B, Oliveira, A., 2009. A modeling-based analysis of processes driving wave-dominated inlets. Continental Shelf Research, 29/5-6: 819 - 834.

Bertin, X., Bruneau, N.,Breilh, J.F.,Fortunato, A.B.,Karpytchev,M.,2012.Importance of wave age and resonance in storm surges: the case Xynthia, Bay of Biscay. Ocean Modelling, 42, 16-30.

Bertin, X., Prouteau, E., Letetrel, C., 2013. A significant increase in wave height in the North Atlantic Ocean over the 20th century, Global and Planetary Change, 106: 77-83

Bertin, X., Li, K., Roland, A., Zhang, Y.J., Breilh, J.F., Chaumillon, E. 2014. A modeling-based analysis of the flooding associated with Xynthia, central Bay of Biscay, Coastal Engineering, 94: 80-89.

Bertin, X., Li, K., Roland, A., Bidlot, J.R., 2015. The contribution of short-waves in storm surges: two case studies in the Bay of Biscay, Continental Shelf Research, 96: 1-15.

Breilh, J.F., Bertin, X., Chaumillon, E., Giloy, N., SauzeauT., 2014. How frequent is storminduced flooding in the central part of the Bay of Biscay?,Global and Planetary Change, 122: $161-175$.

Bruneau, N., Dodet, G., Bertin, X., Fortunato, A.B.,2011. Development of a three-dimensional coupled wave-current model for coastal environments, Journal of Coastal Research, Special Issue 64, 986 - 990.

Bulteau, T., Idier, D., Lambert, J., Garcin, M., 2015. How historical information can improve estimation and prediction of extreme coastal water levels: application to the Xynthia event at La Rochelle (France), Natural Hazards and Earth System Science, 15: 11351147.

Carrasco, A.R., Ferreira, O., Matias, A., Freire, P., 2012. Flood hazard assessment and management of fetch-limited coastal environments, Ocean \& Coastal Management, 65: 15-25. 
661

662

663

664

665

666

667

668

669

670

671

672

673

674

675

676

677

678

679

680

681

682

683

684

685

686

687

688

689

690

691

692

693

694

695

696

697

698

699

700

701

702

703

Coles, S., 2001. An Introduction to Statistical Modeling of Extreme Values.Springer, Berlin, 210pp.

Demerliac, M. A., 1974. Calcul du niveau moyen journalier. Annales Hydrographiques du SHOM, 5ème série, 2: 49-57.

Dodet, G. 2013. Morphodynamicmodelling of a wave-dominatedtidal inlet: the Albufeiralagoon, Ph.D. Dissertation, Université de La Rochelle, 181 pp.

Dodet, G., Bertin, X., Taborda, R., 2010.Wave climate variability in the North-East Atlantic Ocean over the last six decades. Ocean Modeling, 31 (3-4), 120-131.

Eliot, M., 2010. Influence of interannual tidal modulation on coastal flooding along the Western Australian coast, Journal of Geophysical Research, 115/C11013, DOI: 10.1029/2010JC006306.

Fanjul, E.A., Gomez, B.P., Carretero, J.C., Arevalo, I.R.S., 1998. Tide and surge dynamics along the Iberian Atlantic coast, OceanologicaActa, 21/2: 131-143.

Fortunato, A.B., Pinto,L. Oliveira,A., FerreiraJ.S., 2002. Tidally generated shelf waves off the western Iberian coast, Continental Shelf Research, 22/14: 1935-1950

Fortunato, A.B., Bruneau,N.,Azevedo, A.,Araújo, M.A.V.C.,Oliveira, A.,2011. Automatic improvement of unstructured grids for coastal simulations, Journal of Coastal Research, Special Issue 64: 1028-1032.

Fortunato, A.B., Rodrigues, M.,Dias, J.M.,Lopes, C.,Oliveira,A.,2013. Generating inundation maps for a coastal lagoon: A case study in the Ria de Aveiro (Portugal), Ocean Engineering, 64: 60-71.

Freitas, J.G., Dias, J.A., 2013. 1941 windstorm effects on the Portuguese Coast. What lessons for the future? Journal of Coastal Research, Special Issue 65: 714-719. DOI: 10.2112/SI65-121.

Guerreiro, M., Fortunato, A.B., Freire, P., Rilo, A., Taborda, R., Freitas, M.C., Andrade, C., Silva, T., Rodrigues, M., Bertin, X., Azevedo, A., 2015. Evolution of the hydrodynamics of the Tagus estuary (Portugal) in the $21^{\text {st }}$ century.Revista de Gestão Costeira Integrada /JournalofIntegratedCoastal Zone Management, 15/1: 65-80.DOI: 10.5894/rgci515.

Haigh, I.D., Nicholls, R., Wells, N., 2010. A comparison of the main methods for estimating probabilities of extreme still water levels. Coastal Eng. 57, 838-849.

Haigh, I.D., MacPherson, L.R., Mason, M.S., Wijeratne, E.M.S., Pattiaratchi, C.B., Crompton, R.P., George, S., 2014a.Estimating present day extreme water level exceedance probabilities around the coastline of Australia: tropical cyclone-induced storm surges.Climate Dynamics, 42/1-2: 139-157.

Haigh, I.D., Wijeratne, E.M.S., MacPherson, L.R., Pattiaratchi, C.B., Mason, M.S., Crompton, R.P., George, S., 2014b. Estimating present day extreme total water level exceedance probabilities around the coastline of Australia: tides, extra-tropical storm surges and mean sea level. Climate Dynamics, 42/1-2: 121-138.

Holman, R.A., 1986. Extreme value statistics for wave run-up on a natural beach.Coastal Engineering, 9: 527-544.

Horsburgh, K.J., Wilson, C., 2007. Tide-surge interaction and its role in the distribution of surge residuals in the North Sea, Journal of Geophysical Research, 112, C08003.

Idier, D., Dumas, F., Muller, H., 2012. Tide-surge interaction in the English Channel, 
NaturalHazards and Earth System Science, 12: 3709-3718.

Lopes, C.L., Dias, J.M., 2015. Assessment of flood hazard during extreme sea levels in a tidally dominated lagoon, Natural Hazards, 77:1345-1364

Marcos, M., Chust, G. Jordà, G., Caballero,A., 2012. Effect of sea-level extremes on the western Basque coast during the 21st century, Climate Research, 51:237-248.

Mazas, F., Kergadallan, X.,Garat,P.,Hamm, L., 2014.Applying POT methods to the revised Joint Probability Method for determining extreme sea levels, Coastal Engineering, 91: 140-150.

Menendez, M., Woodworth, P.L. 2010.Changes in extreme high water levels based on a quasi-global tide-gauge data set, Journal of Geophysical Research Oceans, 115.

Nicholls, R.J., Wong, P.P., Burkett, V.R., Codignotto, J.O., Hay, J.E., McLean, R.F., Ragoonaden, S., Woodroffe, C.D., 2007. Coastal systems and low-lying areas. Climate Change 2007: Impacts, Adaptation and Vulnerability. Contribution of Working Group II to the Fourth Assessment Report of the Intergovernmental Panel on Climate Change, M.L. Parry, O.F. Canziani, J.P. Palutikof, P.J. van der Linden and C.E. Hanson, Eds., Cambridge University Press, Cambridge, UK, 315-356.

Pairaud, I.L., Lyard, F., Auclair, F., Letellier, T., Marsaleix, P., 2008. Dynamics of the semidiurnal and quarter-diurnal internal tides in the Bay of Biscay. Part 1: barotropic tides. Continental Shelf Research, 28: 1294-1315.

Pereira, C., Coelho, C., 2013. Coastal risk maps due to wave action, Revista de GestãoCosteiralntegrada / Journal of Integrated Coastal Zone Management, 1371: 2743 (in Portuguese).

Perini, L., Calabrese, L., Salerno, G., Ciavola, P., Armaroli, C., 2015. Evaluation of coastal vulnerability toflooding: comparison of two differentmethodologies adopted by theEmiliaRomagna Region (Italy), Natural Hazards and Earth System Science Discussions, 3: 4315-4352. DOI:10.5194/nhessd-3-4315-2015

Pinto, L., Fortunato, A.B., Zhang,Y., Oliveira, A., Sancho, F.E.P., 2012. Development and validation of a three-dimensional morpho-dynamic modelling system for non-cohesive sediments, Ocean Modelling, 57-58: 1-14.

Pond, S.,Pickard, G.L., 1998. Introductory dynamical oceanography, Butterworth-Heinmann.

Pugh, D., Vassie, J., 1980. Applications of the joint probability method for extreme sea-level computations. Proc. Inst. Civ. Eng. 69, 959-975.

Quevauviller, P., 2011.Adapting to climate change: reducing water-related risks in Europe EU policyand research considerations, Environmental Science and Policy, 14: 722-729.

Rego, J.L., Li, C., 2010. Nonlinear terms in storm surge predictions: Effect of tide and shelf geometry with case study from Hurricane Rita, J. Geophys. Res., 115, C06020, doi:10.1029/2009JC005285.

Rodrigues, M., Oliveira,A., Queiroga,H., Fortunato, A.B., Zhang, Y.J., 2009). Threedimensional modeling of the lower trophic levels in the Ria de Aveiro (Portugal), Ecological Modelling, 220/9-10: 1274-1290

Rodrigues, M., Oliveira, A.,Guerreiro, M.,Fortunato, A.B.,Menaia, J.,David, L.M.,Cravo, A.,2011. Modeling fecal contamination in the Aljezur coastal stream (Portugal), Ocean Dynamics, 61/6: 841-856 
Rodrigues, M., Oliveira, A., Queiroga, H., Brotas, V., 2012. Seasonal and diurnal water quality and ecological dynamics along a salinity gradient (Mira channel, Aveiro lagoon, Portugal), Procedia Environmental Sciences, 13:899-918.

Roland, A., Zhang, Y.J., Wang, H.V., Meng, Y., Teng, Y.-C., Maderich, V., Brovchenko, I., Dutour-Sikiric, M., Zanke, U., 2012. A fully coupled 3D wave-current interaction model on unstructured grids, Journal of Geophysical Research, 117, C00J33, DOI: 10.1029/2012JC007952.

Saha, S., Moorthi, S., Pan, H.-L., Wu, X., Wang, J., Nadiga, S., et al. 2010. The NCEP Climate Forecast System Reanalysis. Bulletin of the American Meteorological Society, 91(8), 1015-1057. doi:10.1175/2010BAMS3001.1

Serafin, K.A., Ruggiero, P., 2014. Simulating extreme total water levels using a timedependent, extreme value approach, Journal of Geophysical Research: Oceans, 119/9: 6305-6329.

Simon, B., 2007. La marée océanique côtière. Collection "Synthèses". Institut Océanographique, $433 \mathrm{pp}$.

Stockdon, H.F., Holman, R.A., Howd, P.A., Sallenger Jr., A.H., 2006. Empirical parameterization of setup, swash and runup. Coastal Engineering, 53: 573-588.

Stopa, J.E., Cheung, K.F., 2014. Intercomparison of wind and wave data from the ECMWF Reanalysis Interin and the NCEP Climate Forecast System Reanalysis, Ocean Modeling, 75: 65-83.

Tavares, A.O., Santos, P.P., Freire, P., Fortunato, A.B., Rilo, A., Sá, L., 2015. Flooding hazard in the Tagus estuarine area: the challenge of scale in vulnerability assessments.Environmental Science \& Policy, 5 1: 238-255. DOI: 10.1016/j.envsci.2015.04.010.

Tawn, J.A., 1988. An extreme value theory model for dependent observations.J. Hydrol. 101, 227-250.

Tawn, J., 1992. Estimating probabilities of extreme sea-levels.Appl. Statist. 41, 77-93.

Tawn, J.A., Vassie, J.M., 1989. Extreme sea levels: the joint probability method revisited and revised, Proceedings of the Institution of Civil Engineers, Part 2, 87: 429-442.

Weiss, J., Bernardara, P., Benoit, M., 2014. Modeling intersite dependence for regional frequency analysis of extreme marine event, Water Resources Research, 50: 59265940, doi:10.1002/2014WR015391

Wöppelmann, G., Pouvreau, N., Coulomb, A., Simon, B., Woodworth, P.L., 2008. Tide gauge datum continuity at Brest since 1711: France's longest sea-level record, Geophysical Research Letters, 35: L22605.

Zhang, H., Sheng, J., 2013. Estimation of extreme sea levels over the eastern continental shelf of North America, Journal of Geophysical Research: Oceans, 118: 6253-6273.

Zhang, Y.-L., Baptista, A.M., 2008. SELFE: A semi-implicit Eulerian-Lagrangian finite-element model for cross-scale ocean circulation. Ocean Modelling, 21/3-4: 71-96.

Zhang, Y., Witter, R., Priest, R., 2011. Tsunami-tide interaction in 1964 Prince William Sound tsunami.Ocean Modelling, 40/3-4, 246-259. 


\section{Figures}

789

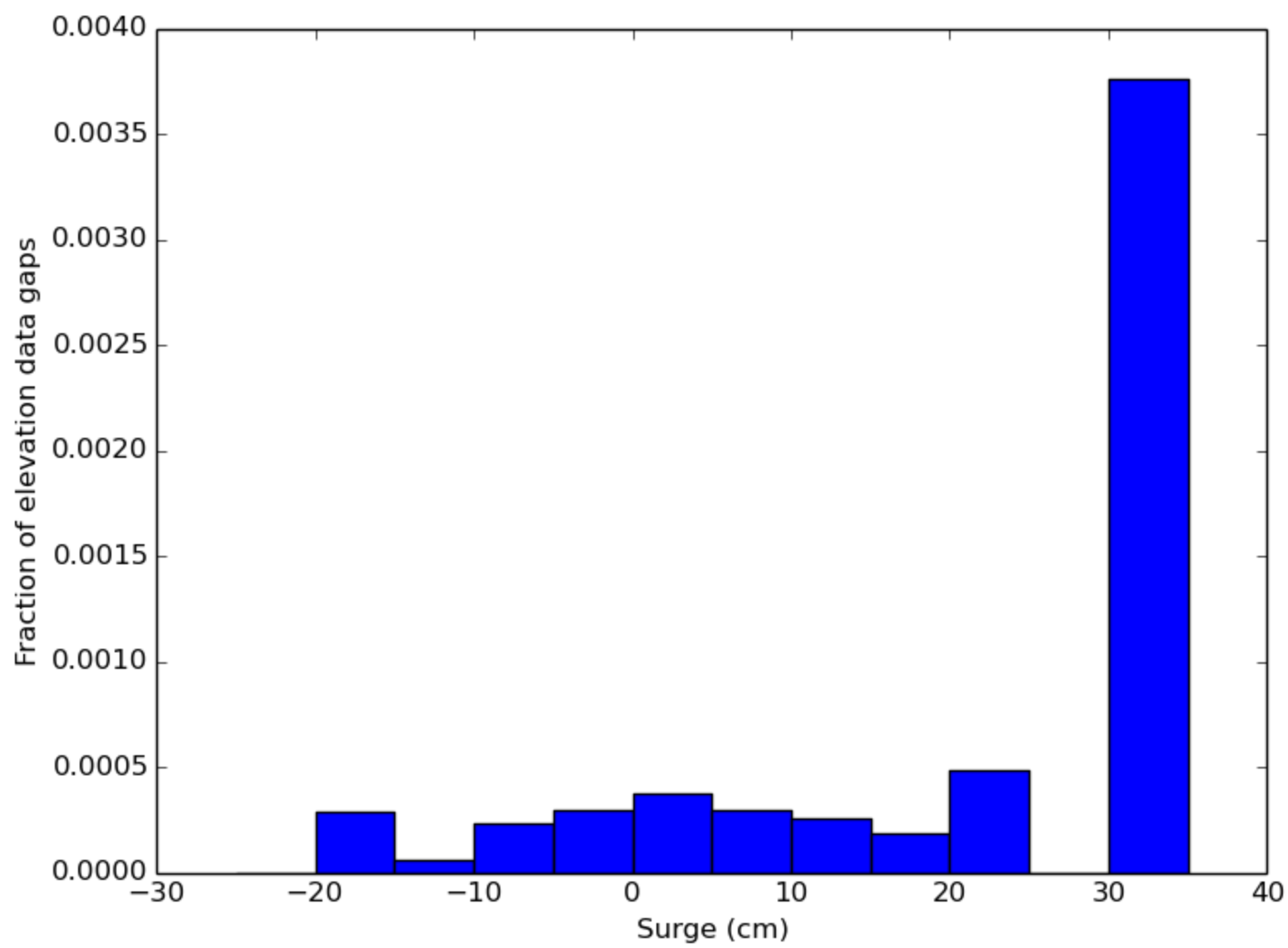

790

791

792

793

794

Figure 1. Fraction of the beginning of data gaps in the Cascais for different ranges of low frequency surges. The surges were obtained by filtering the results of water elevations obtained with the regional model described below with a Demerliac filter to remove daily and higher frequencies. Results suggest that data gaps occur more frequently during periods with extreme events. Data spans the period 1977-2010. 


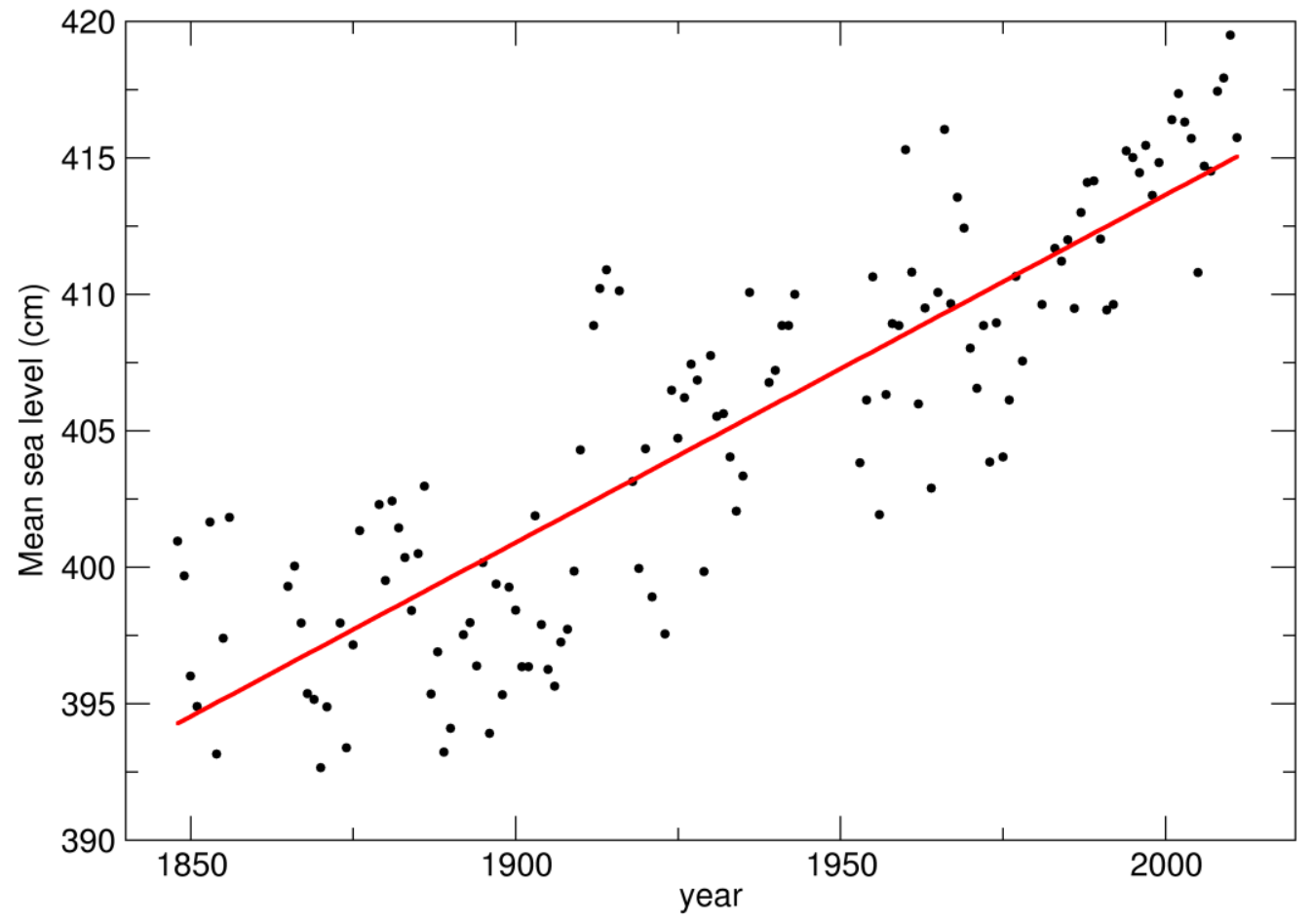

795 

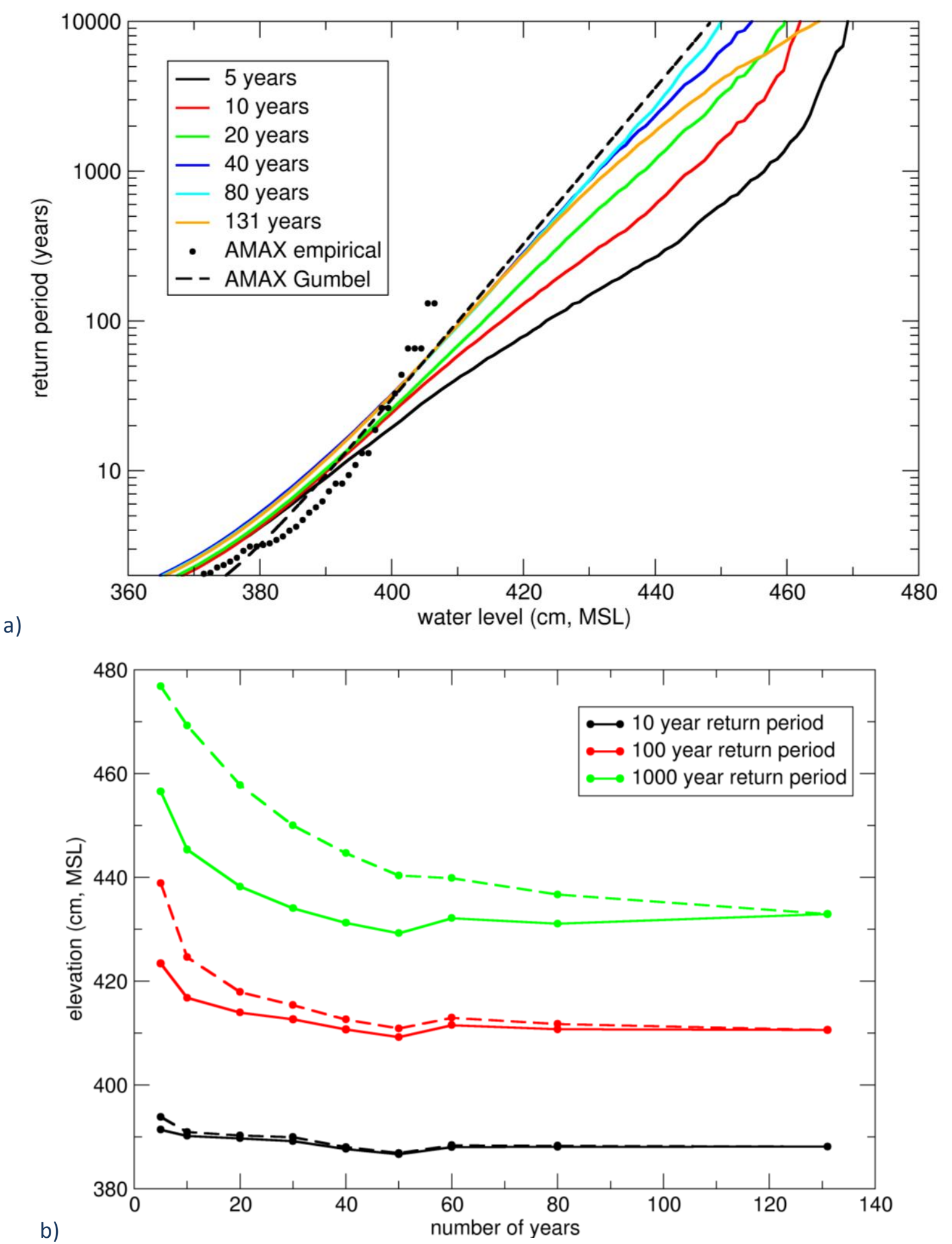

Figure 3. Convergence analysis: a) return period as a function of the maximum elevation for different numbers of years of data; results from the direct application of the AMAX method to the observations are included for comparison; b) convergence of the maximum elevation for return periods of 10, 100 and 1000 years. The dashed lines were computed including data from 1987, the year with the maximum registered storm surge at Brest. 


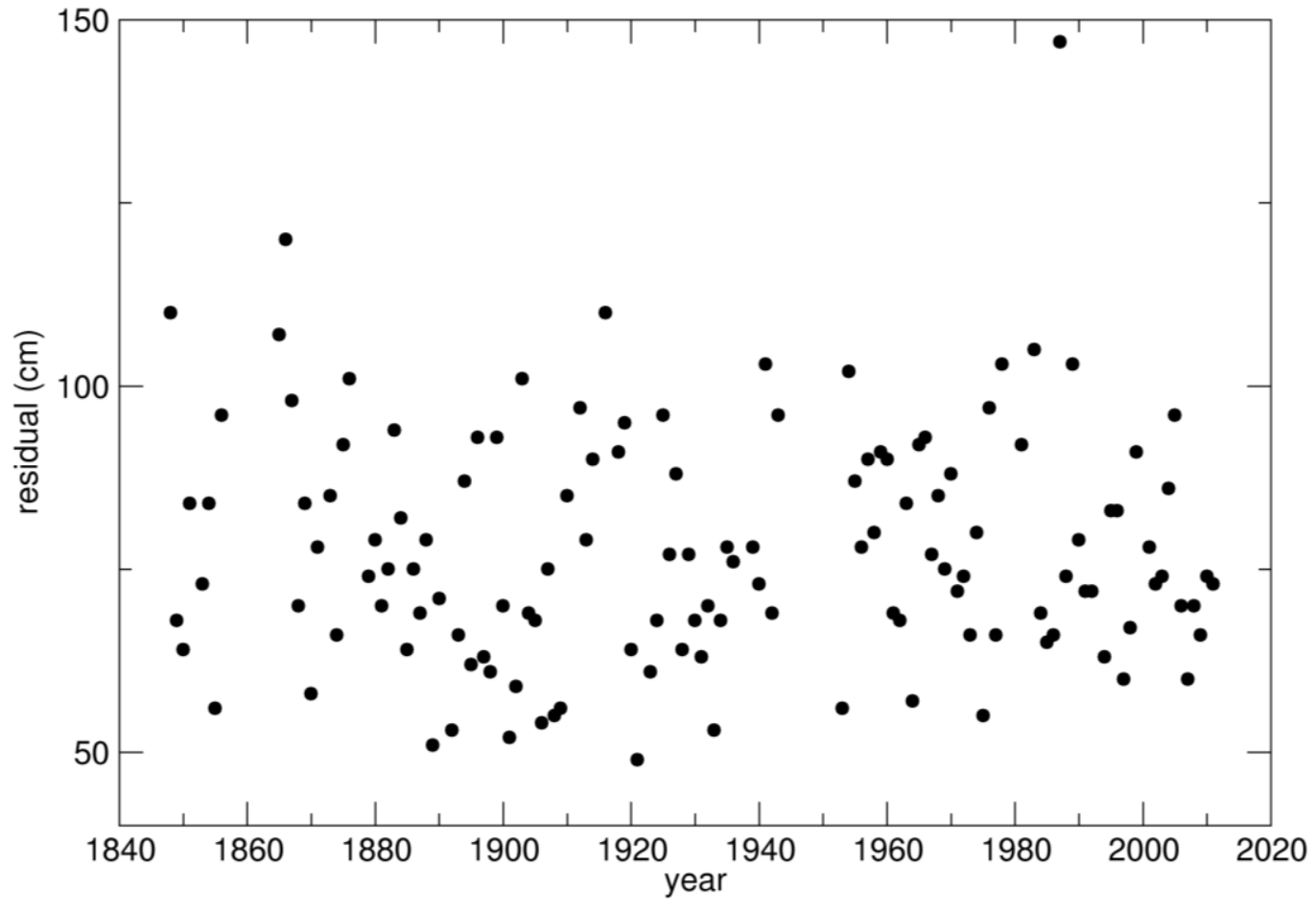




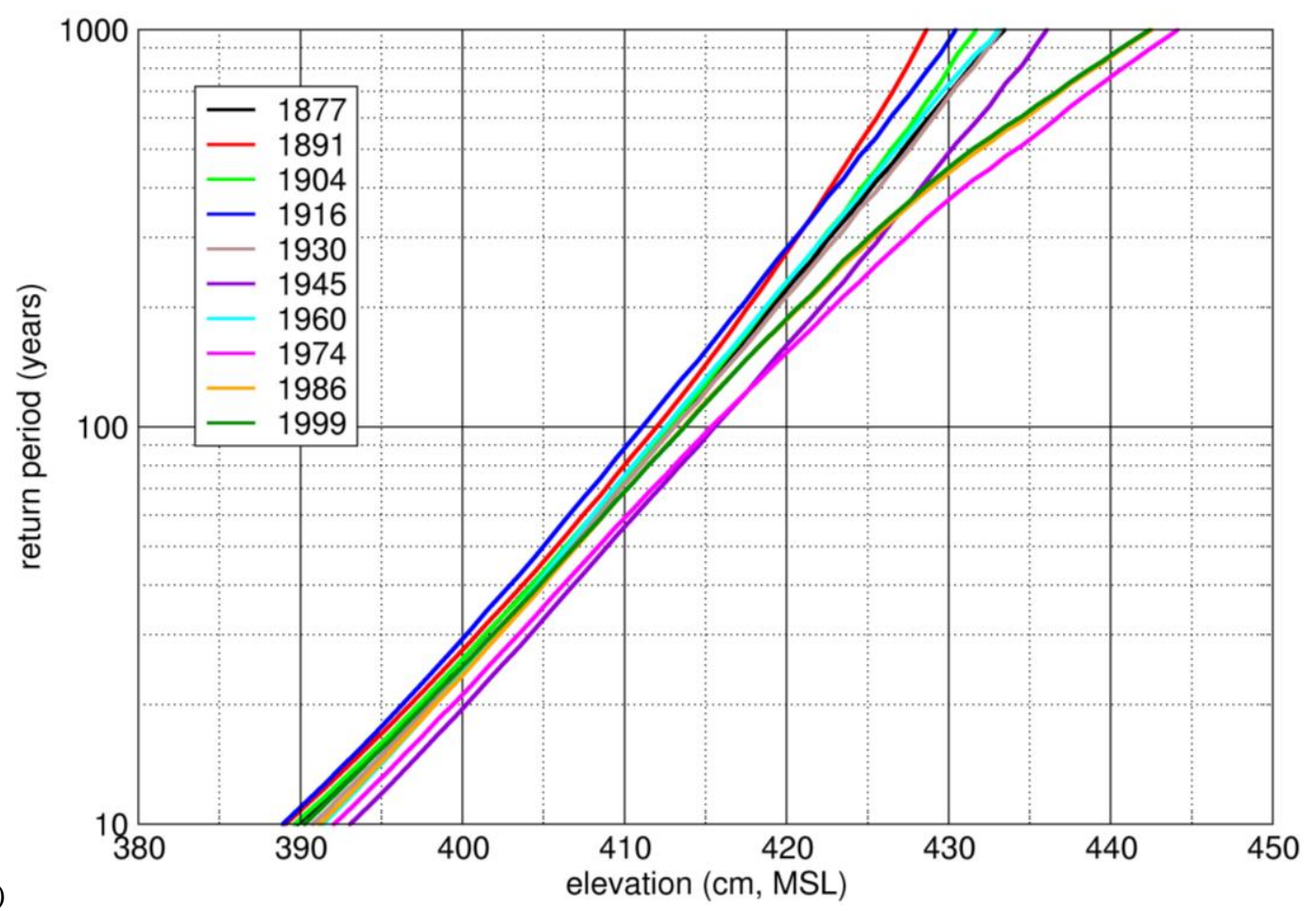

a)

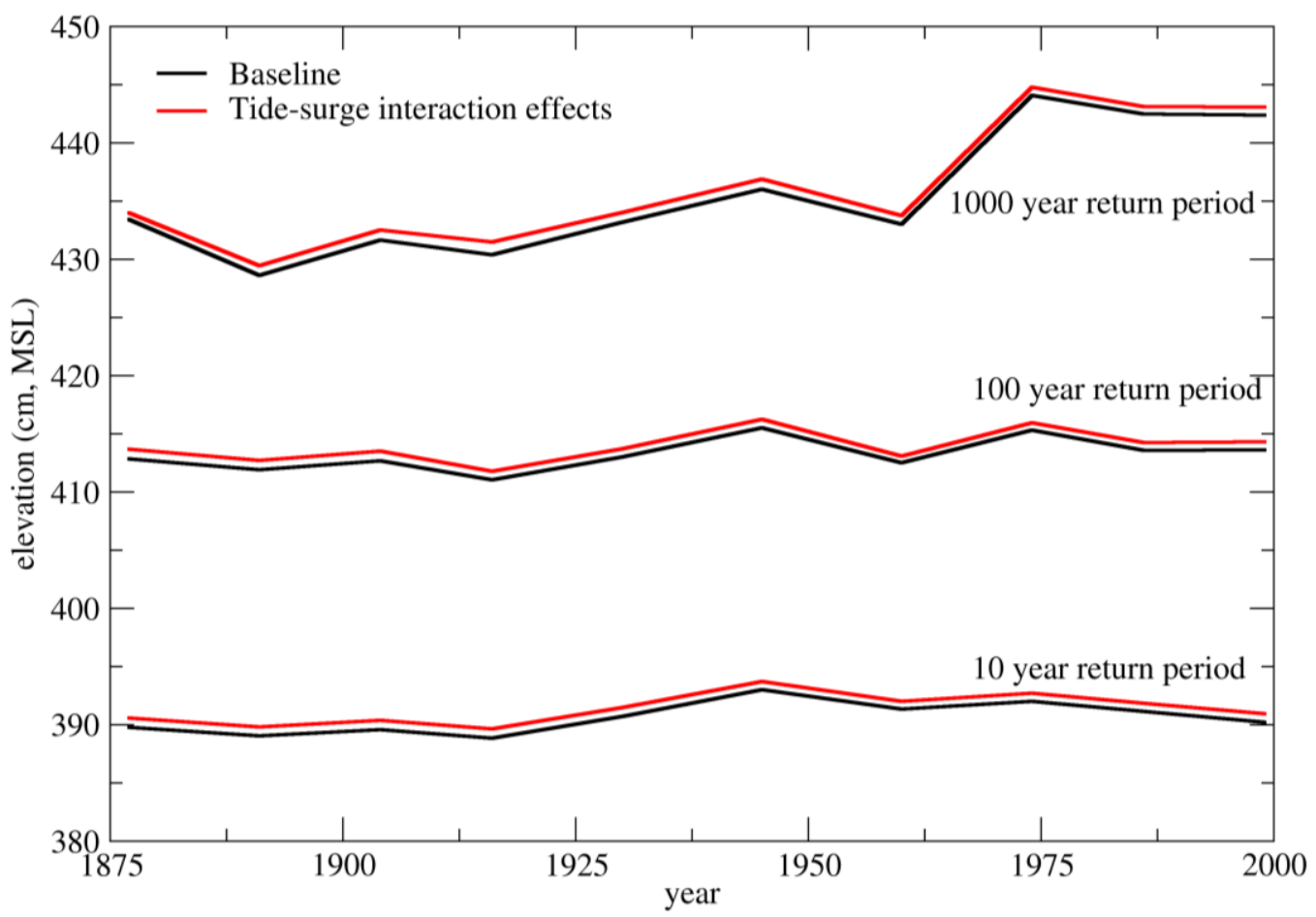

814

815

816

817

818 b)

Figure 5. Evolution of extreme sea elevations for different return periods determined using a sliding window with 41 years: a) return period as a function of the maximum elevation; b) evolution of the maximum elevation for selected return periods and effect of tide-surge interactions. 


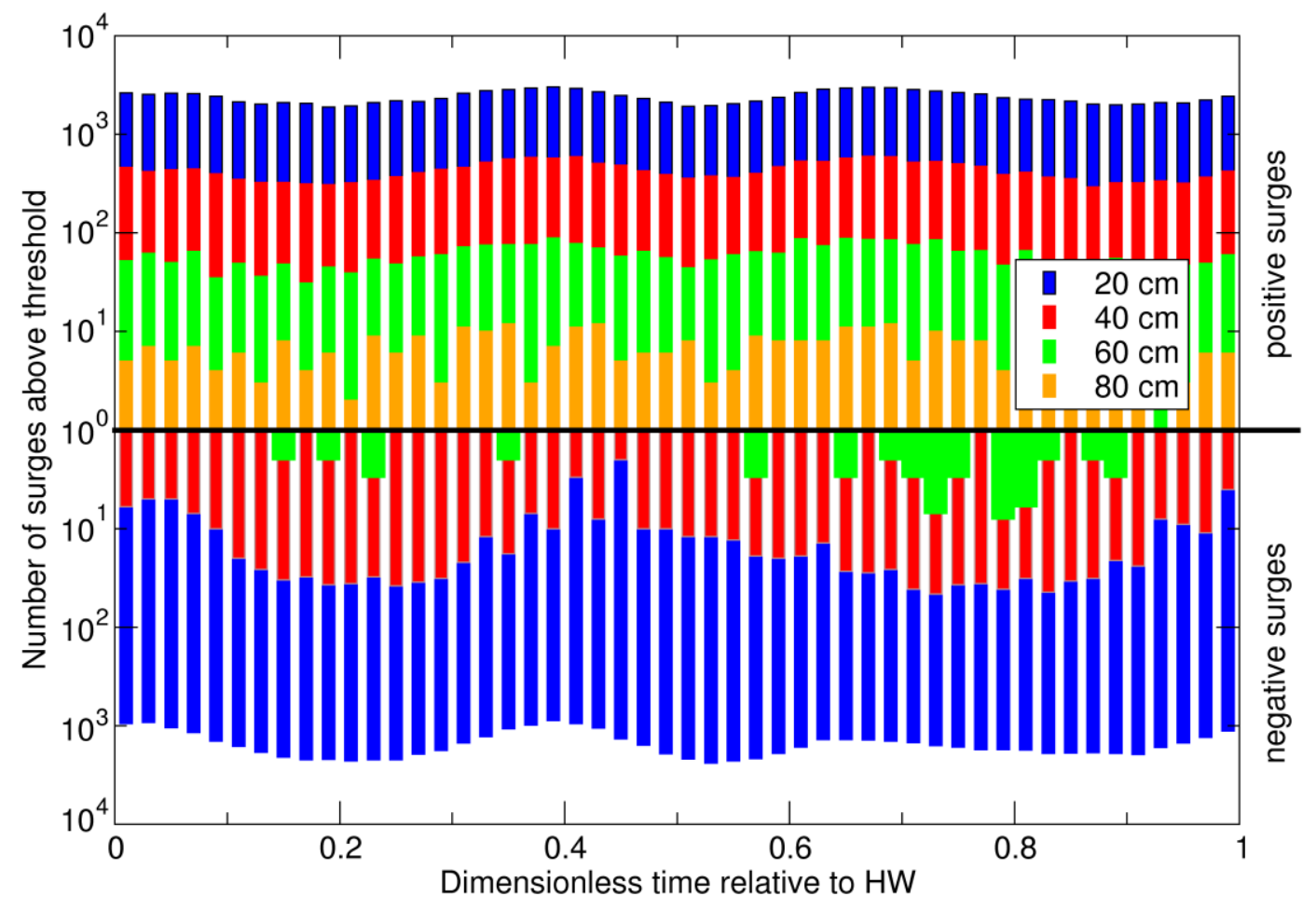

819

Figure 6. Illustration of tide-surge interactions at Brest for the 131 years analyzed. The horizontal axis represents the

821 time between two consecutive high water tides. The upper (lower) bars represent the number of positive (negative) 


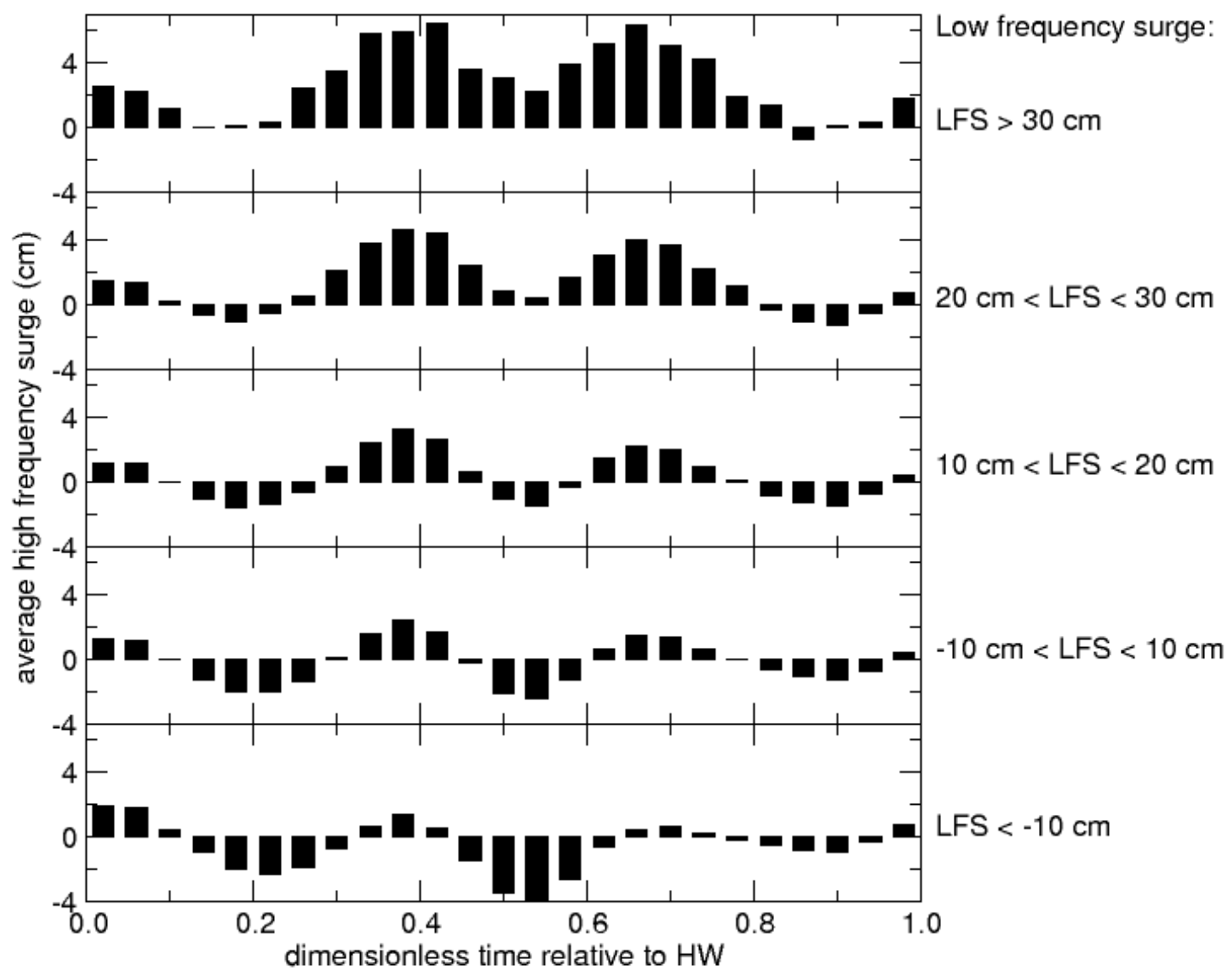

Figure 7. Average surge as a function of the tidal phase (horizontal axis) and low frequency surge (LFS, obtained by applying a Demerliac filter to the observations). 


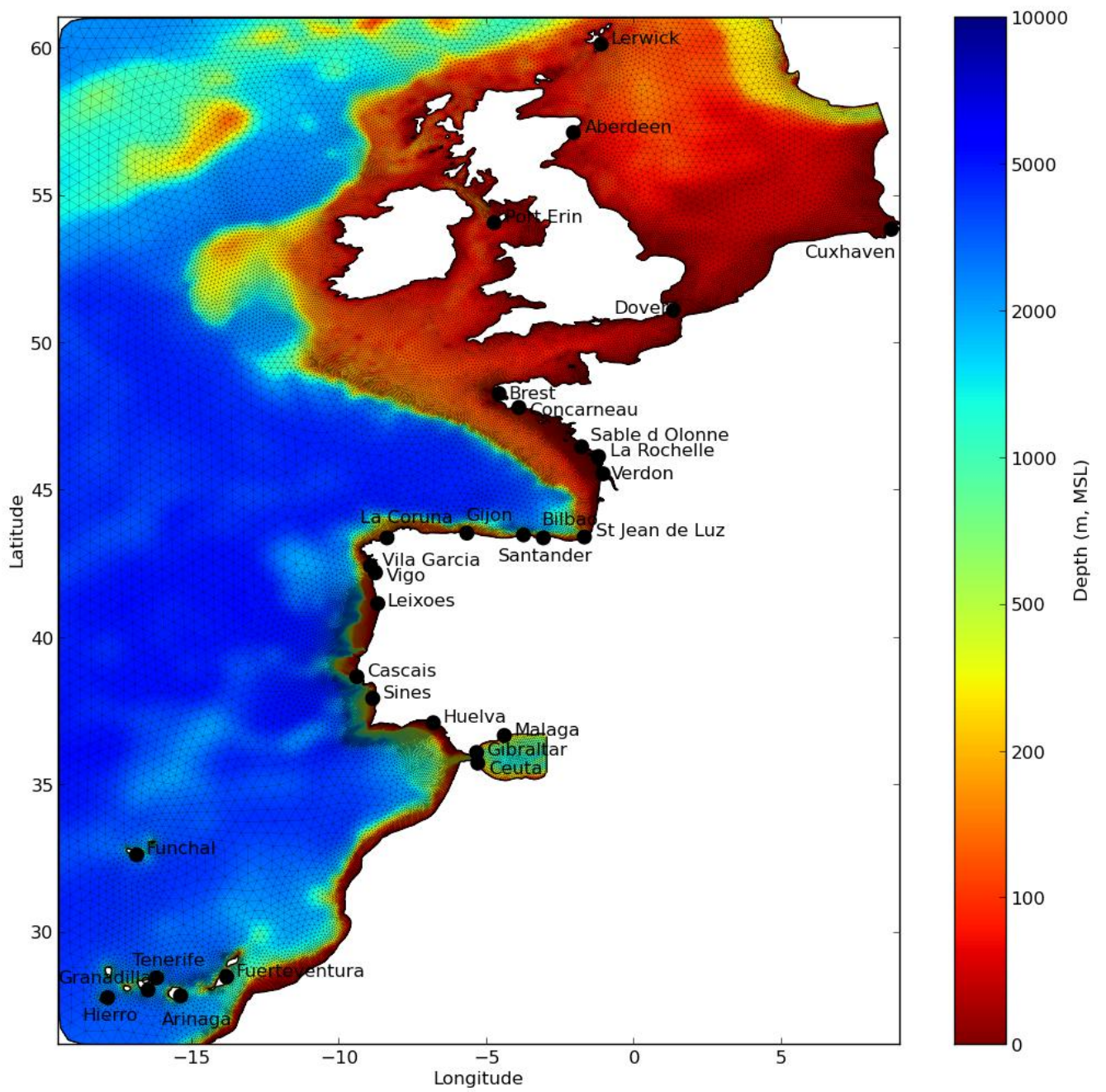

Figure 8.Finite element grid, bathymetry and tidal stations. 

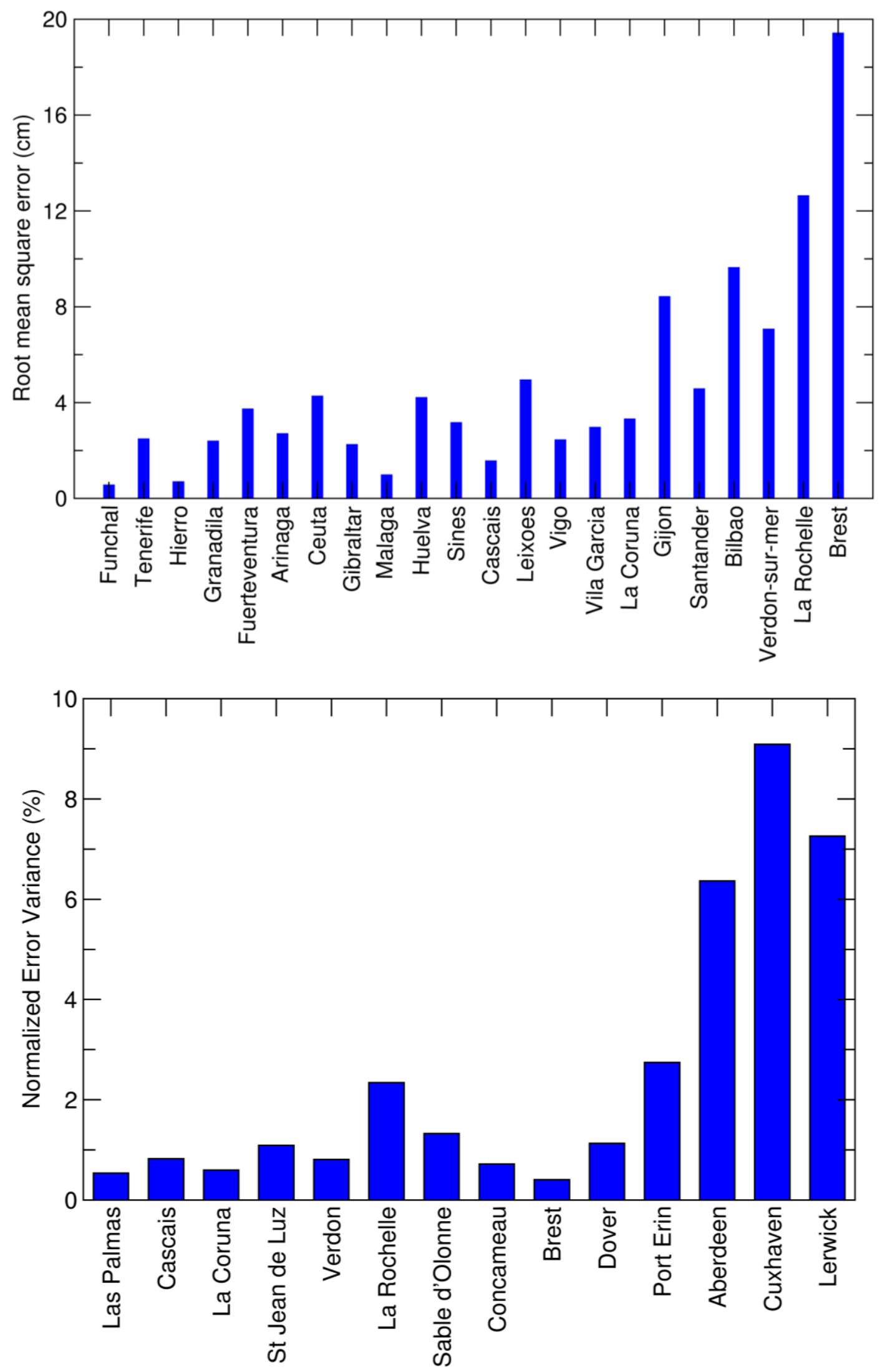


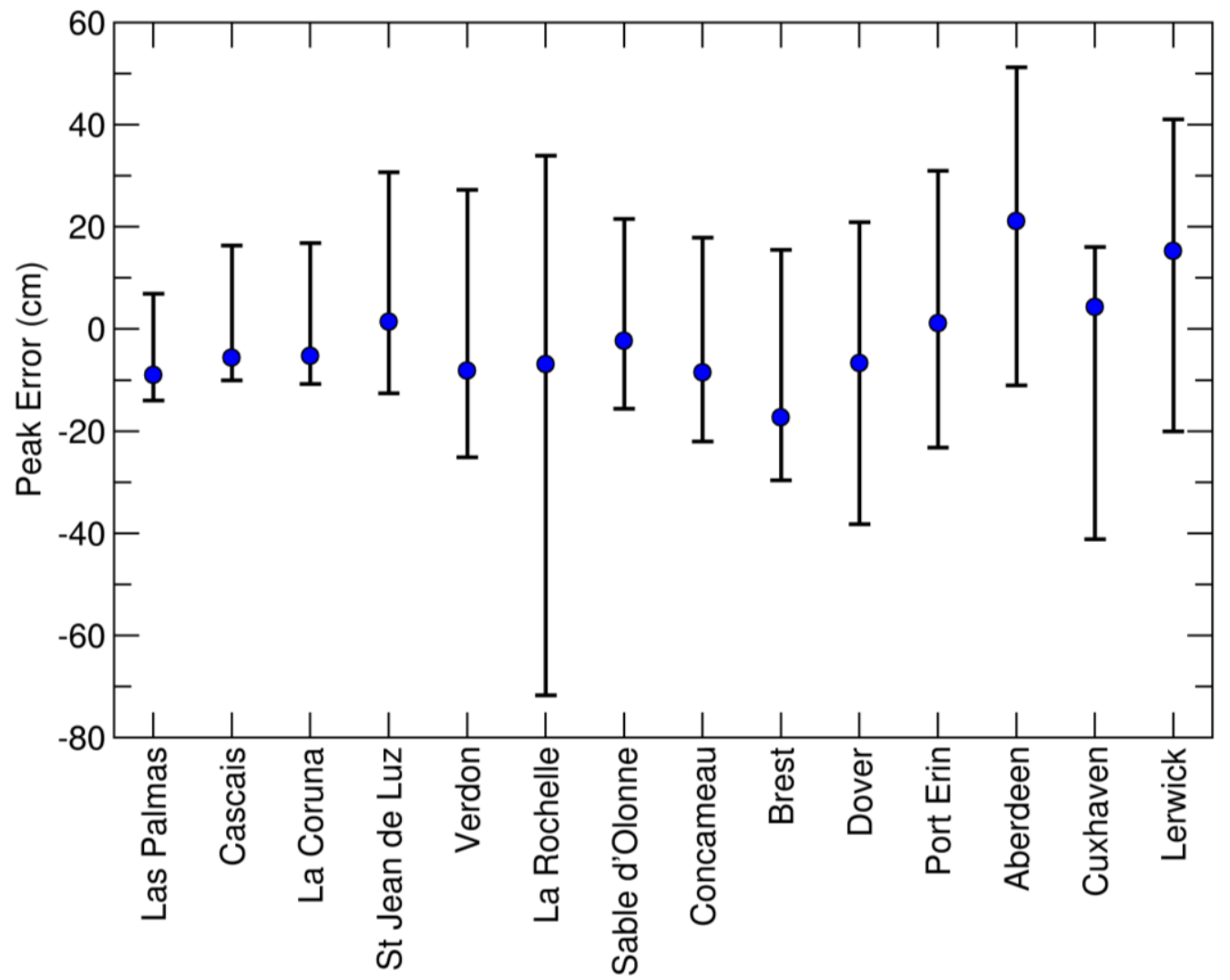

833

c)

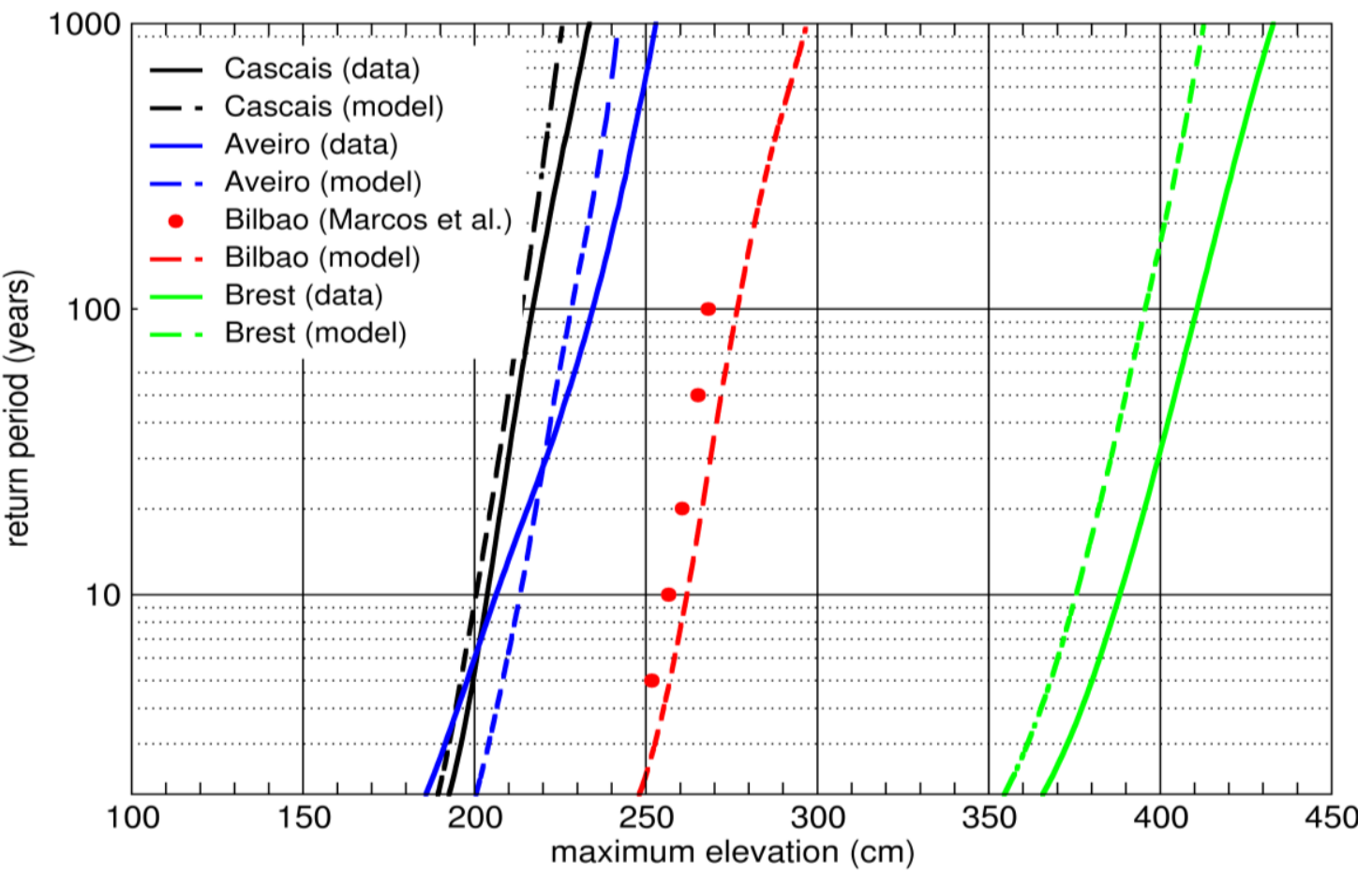

834

835

836

837

838

839

840 d)

Figure 9. Model validation: a) root mean square errors of the tidal model for the 5 major constituents (M2, S2, N2, O1, K1); b)normalized error variance; c) peak errors at various stations during the 2009-2010 winter; the peak error range indicates the maximum positive and negative differences between the observed and the modeled high tides; d) comparison of the return periods of extreme sea levels computed with the present model with those from a different model (Bilbao, from Marcos et al., 2012) or data (Cascais, from Guerreiro et al., 2015; Aveiro, from Fortunato et al., 2013 and Brest). 


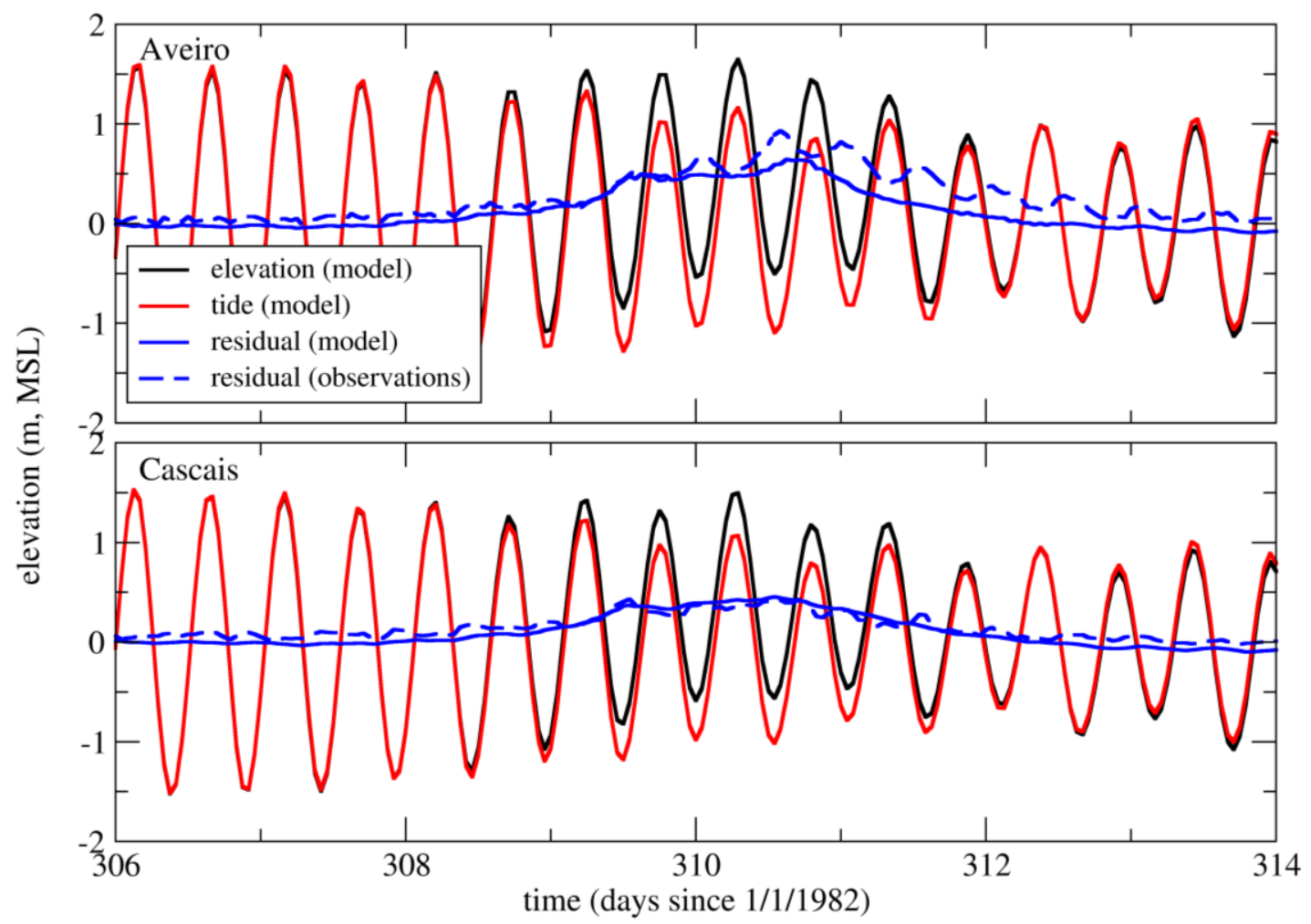

841

842

843
Figure 10.Simulation of a storm surge in November 1982. Residuals obtained from observations were computed by Fortunato et al. (2013) and Guerreiroet al. (2015) for Aveiro and Cascais, respectively. 

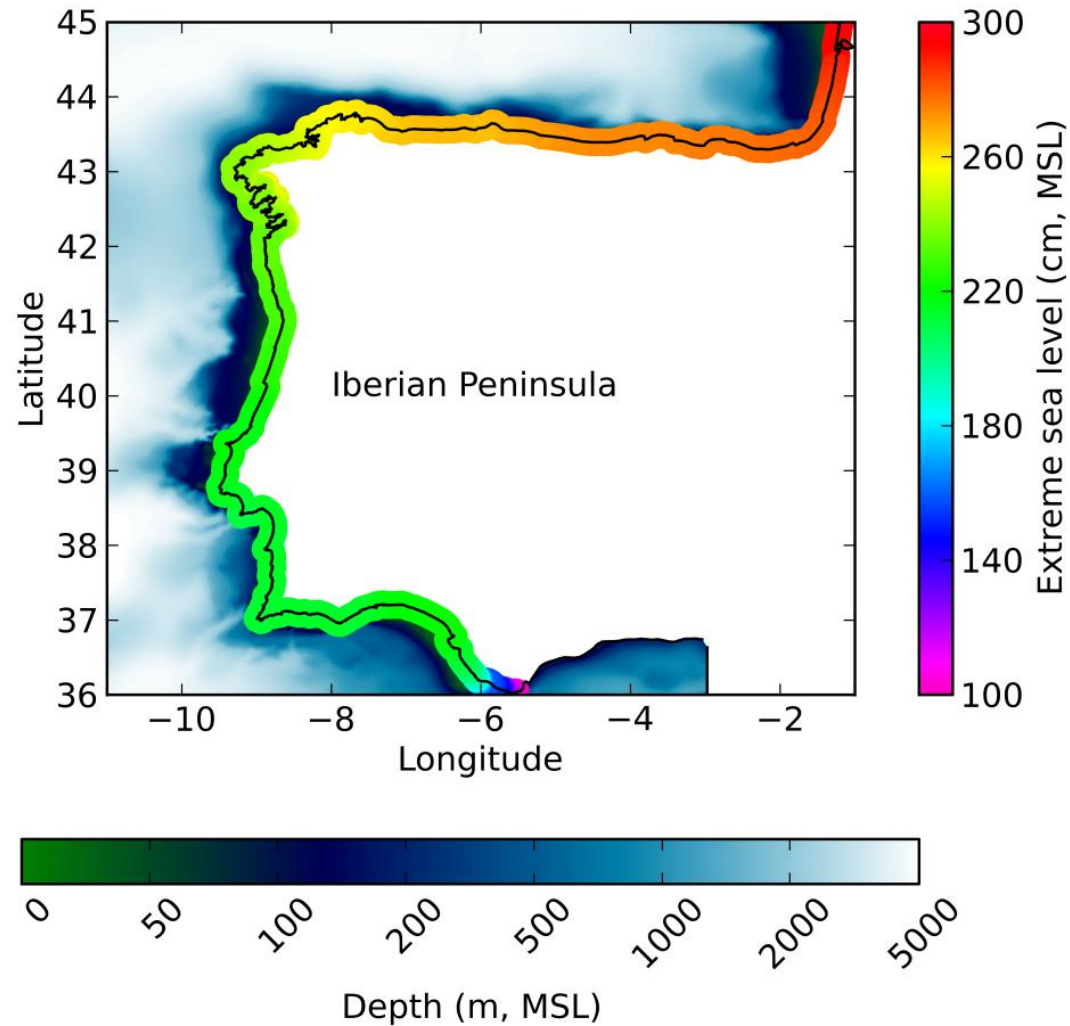

844

845

846
Figure 11. Extreme sea levels along the Iberian Atlantic coast for a return period of $\mathbf{1 0 0}$ years. 


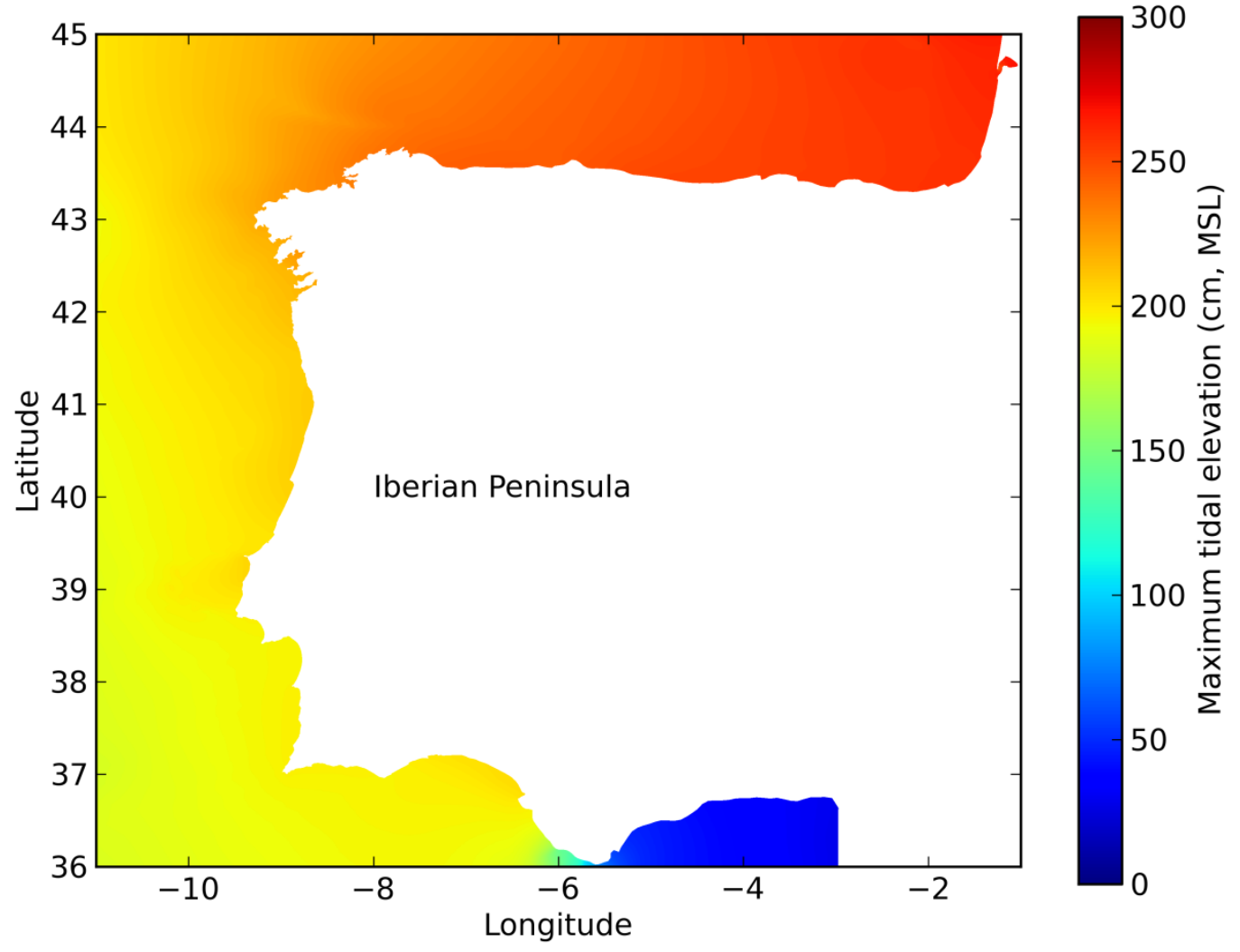

847

848

Figure 12.Maximum tidal elevations for a 1 year simulation.

849

850 

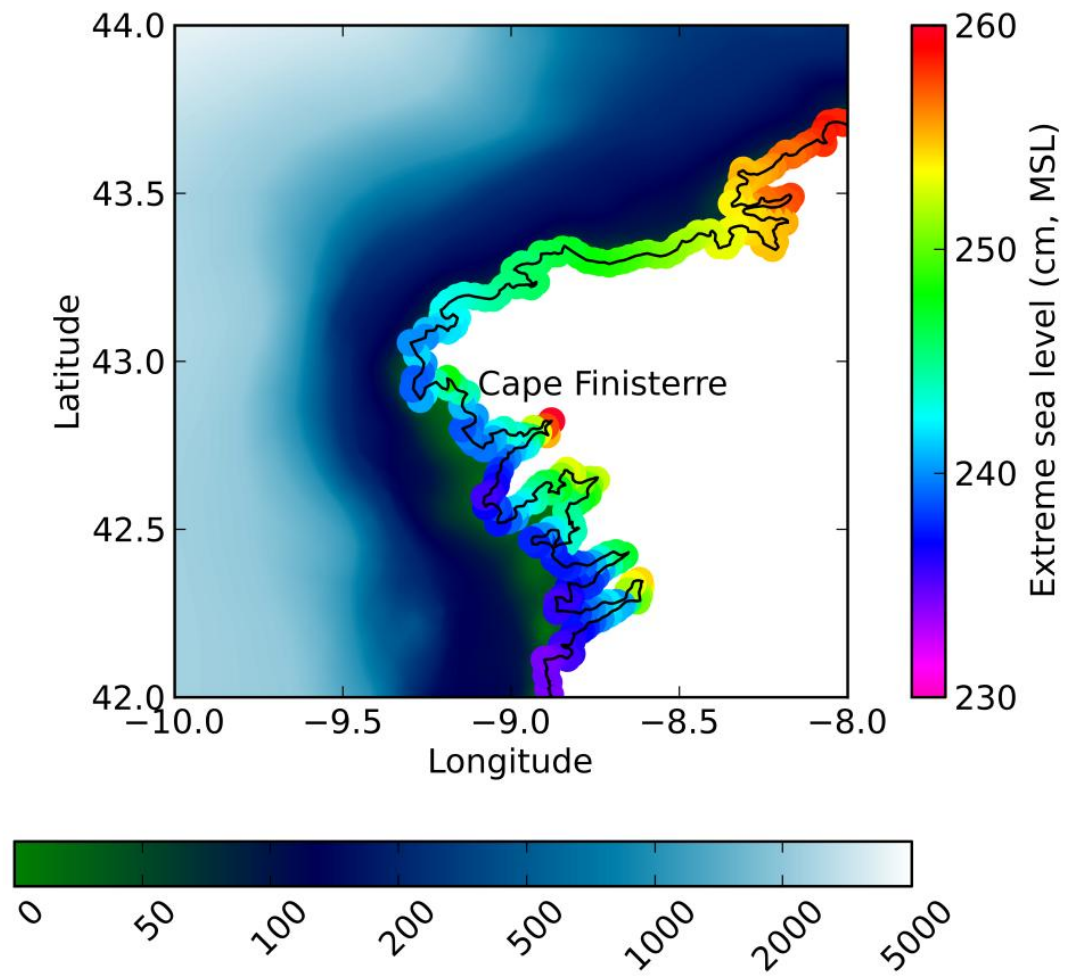

Depth (m, MSL)

851

Figure 13.Extreme sea levels in the north-western Iberian Atlantic coast for a return period of 100 years.

853 

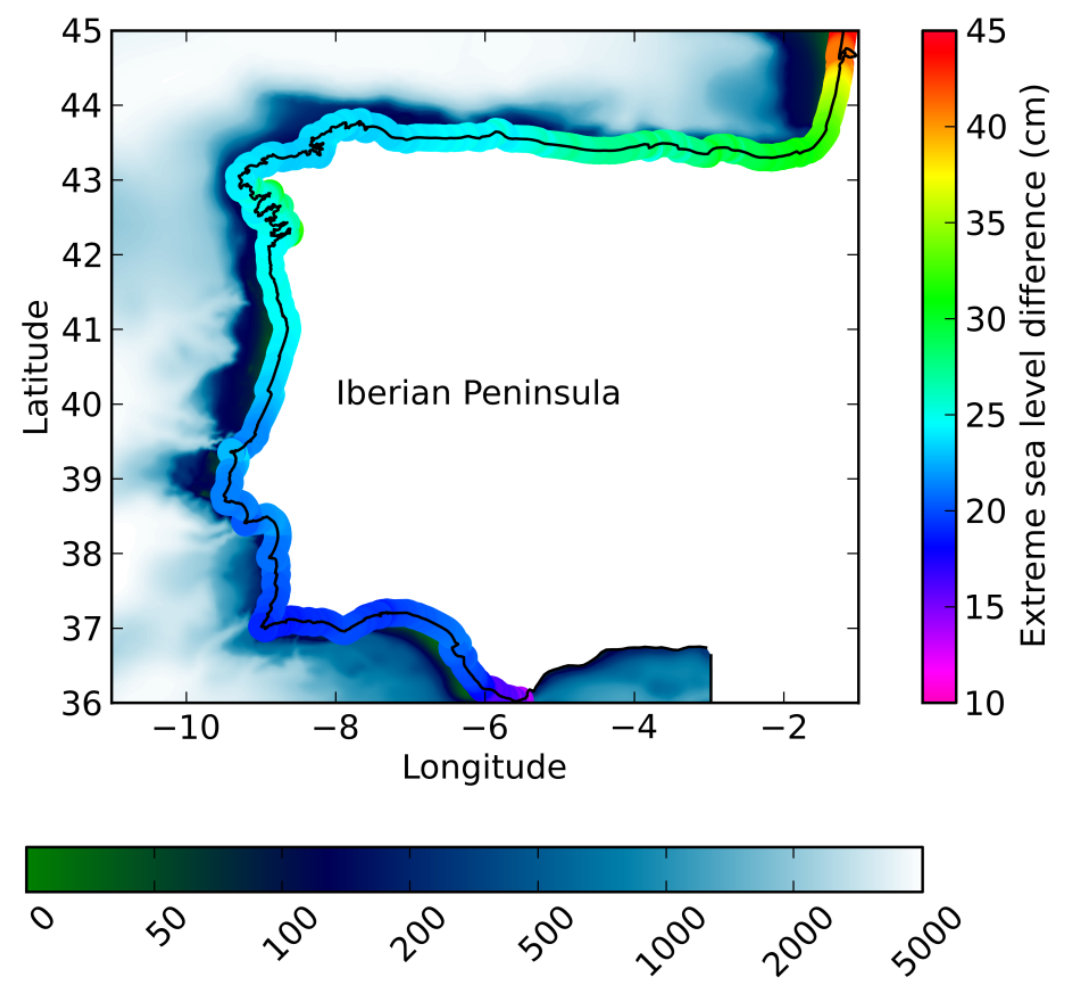

854

855

856

857

858

Depth (m, MSL)

Figure 14.Difference between the extreme sea levels for return periods of 1000 and 20 years. 


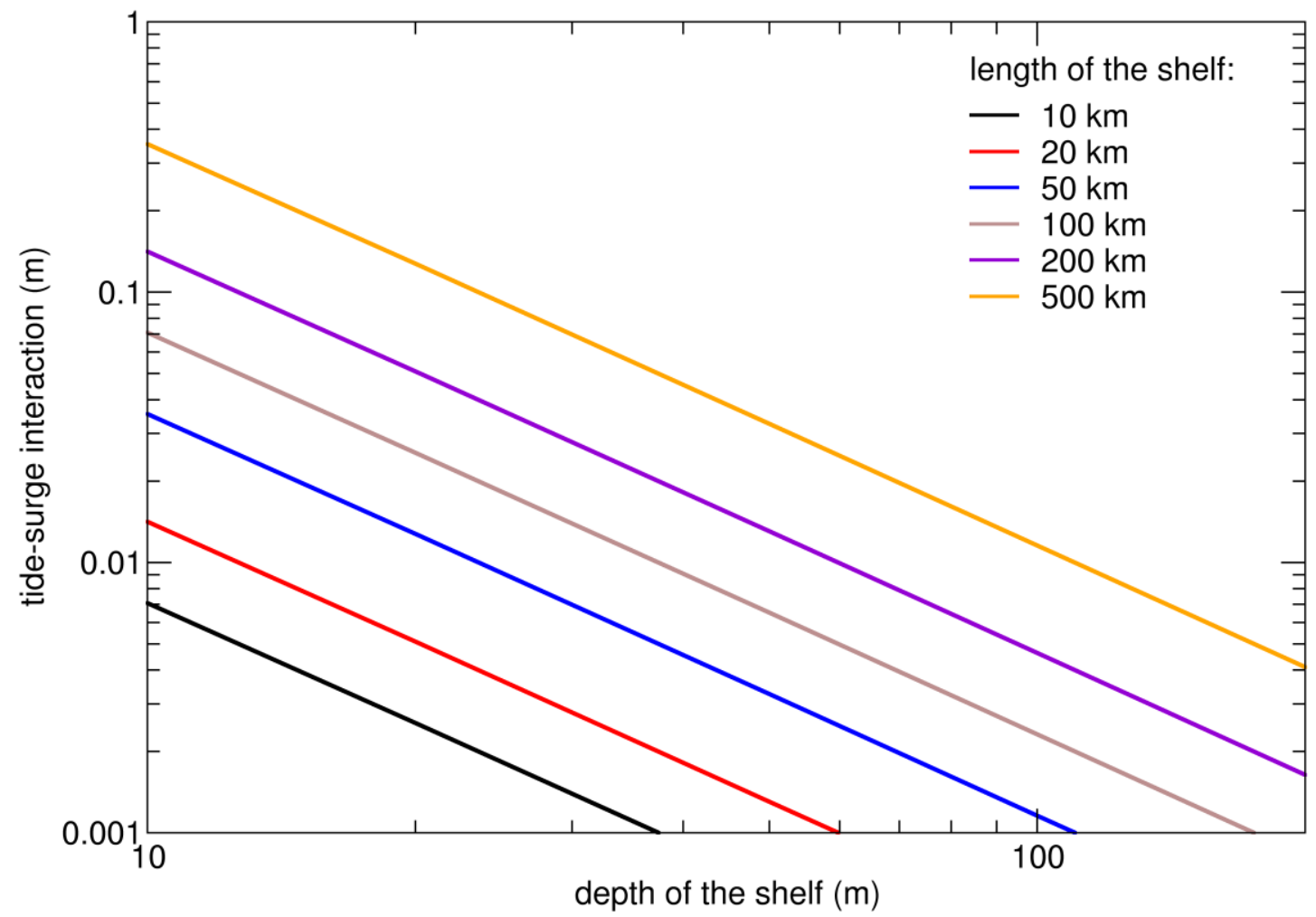

Figure A. 1. Estimation of tide-surge interaction effects due to changes in tidal celerity associated with surges. The tidal amplitude is taken as $\mathbf{2} \mathrm{m}$, the surge as $0.5 \mathrm{~m}$, and the tidal period as 12 hours. 


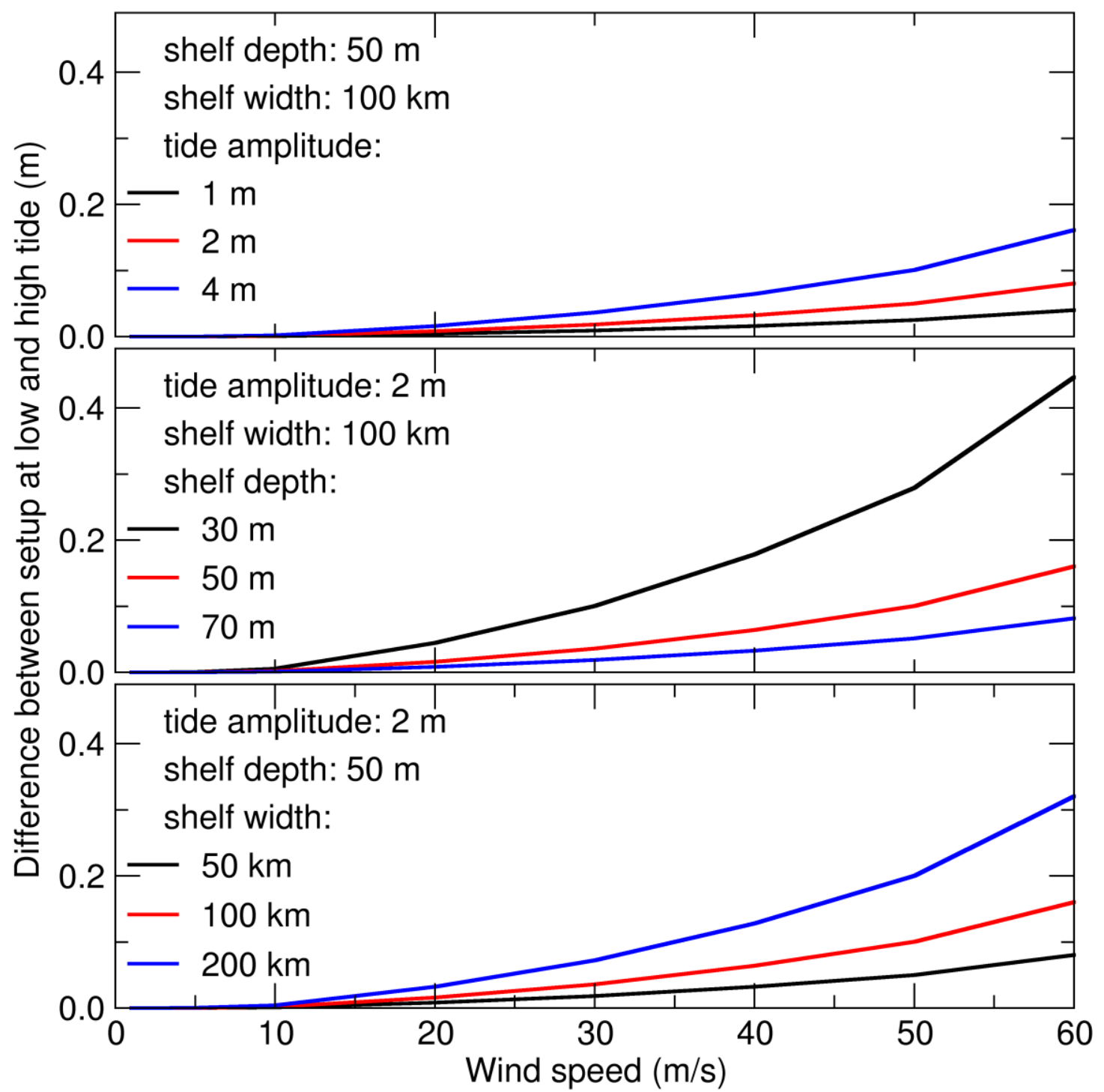

